\title{
The SNARE machinery in mast cell secretion
}

\author{
Axel Lorentz ${ }^{1}$, Anja Baumann ${ }^{1}$, Joana Vitte ${ }^{2,3}$ and Ulrich Blank ${ }^{2,3}$ * \\ 1 Department of Nutritional Medicine, University of Hohenheim, Stuttgart, Germany \\ 2 INSERM UMRS 699, Paris, France \\ ${ }^{3}$ Laboratoire d'Excellence Inflamex, Faculté de Médicine, Site Xavier Bichat, Université Paris-Diderot, Paris, France
}

Edited by:

Marc Benhamou, Institut National de la Santé et de la Recherche Médicale, France

\section{Reviewed by:}

Marc Benhamou, Institut National de la Santé et de la Recherche Médicale France

Laura Eugenia Velazquez, Institut National de la Santé et de la

Recherche Médicale/Université Paris 13, France

\section{*Correspondence:}

Axel Lorentz, Department of

Nutritional Medicine, University of

Hohenheim, Fruwirthstraße 12,

D-70593 Stuttgart, Germany.

e-mail: axel.lorentz@

uni-hohenheim.de;

Ulrich Blank, INSERM UMRS 699,

Université Paris-Diderot, Faculté de

Médecine Site Bichat, 16, rue Henri

Huchard, F-75870 Paris CEDEX 18,

France.

e-mail: ulrich.blank@inserm.fr
Mast cells are known as inflammatory cells which exert their functions in allergic and anaphylactic reactions by secretion of numerous inflammatory mediators. During an allergic response, the high-affinity lgE receptor, $\mathrm{F} c \varepsilon R I$, becomes cross-linked by receptor-bound IgE and antigen resulting in immediate release of pre-synthesized mediators - stored in granules - as well as in de novo synthesis of various mediators like cytokines and chemokines. Soluble N-ethylmaleimide-sensitive factor attachment protein (SNAP) receptors (SNARE) proteins were found to play a central role in regulating membrane fusion events during exocytosis. In addition, several accessory regulators like Munc13, Munc18, Rab GTPases, secretory carrier membrane proteins, complexins, or synaptotagmins were found to be involved in membrane fusion. In this review we summarize our current knowledge about the SNARE machinery and its mechanism of action in mast cell secretion.

Keywords: mast cell, exocytosis, SNARE proteins

\section{INTRODUCTION}

Mast cells are tissue-localized cells that upon activation release a whole variety of inflammatory mediators (Blank and Rivera, 2004; Rivera and Gilfillan, 2006). When released, their role is to protect the body against infectious agents, injury or stress, however, inappropriate or chronic production may also have harmful consequences and engender inflammatory diseases (Bischoff, 2007; Kalesnikoff and Galli, 2008; Abraham and St John, 2010). Mast cells are best-known for the role they play in allergic diseases after stimulation through IgE bound to high-affinity IgE receptors. However, recent years have made clear their general role both in protective and disease-promoting inflammatory responses that involve stimulation through a wide array of surface-expressed receptors including $\operatorname{IgG~Fc}$ receptors, different types of $\mathrm{G}$ protein-coupled receptors, Toll-like receptors, etc. (Bischoff, 2007; Kalesnikoff and Galli, 2008; Abraham and St John, 2010; Beghdadi et al., 2011). While initial therapeutic strategies aiming to restrict mast cell activation largely focused on blocking the activation of the IgE receptor and its early signaling events, targeting the late signaling steps has become a suitable alternative strategy. The latter approach would block the consequences of activation by many different receptor types converging into the same secretory pathways.

With the exception of lipid-derived mediators that are synthesized at the plasma membrane, mast cells secrete their mediators either by a process called degranulation from sources pre-stored in cytoplasmic granules including for example histamine and certain mast cell specific proteases or through carrier vesicles emanating from the Golgi including a large array of cytokines/chemokines (Blank and Rivera, 2004; Sagi-Eisenberg, 2007). Considerable advances have been made in the understanding of the molecular machinery involved in vesicular secretion. In this review we provide an overview of the current knowledge on the mechanisms of mast cell exocytosis as well as our current ideas about its mechanisms of regulation.

\section{CHARACTERISTICS OF MAST CELL EXOCYTOSIS}

Transport of vesicles and exocytosis of mediators are cellular processes that occur in all eukaryotic cells. Newly synthesized mediators must be translocated into the endoplasmic reticulum and then transported to the Golgi apparatus, where secretory cargoes are sorted into a variety of transport carriers for delivery to their final destinations (Glick and Nakano, 2009). Some secretory cells including mast cells are capable of regulated exocytosis (Lacy and Stow, 2011). They store a wide range of factors and immune mediators in pre-formed secretory granules (SG). Like in other hematopoietic cells with SG these are dual-function organelles containing lysosomal hydrolases such as $\beta$-hexosaminidase and cathepsin-D as found in all lysosomes as well as specific secretory inflammatory products (Stinchcombe and Griffiths, 2007). They are therefore often called secretory lysosomes to underline the close connection between endosomal/lysosomal and secretory compartments. Functionally, secretory lysosomes are unusual in 
that they serve both as a degradative and as a secretory compartment (Blott and Griffiths, 2002). Upon activation mast cells release a high amount of granule contents (Blank and Rivera, 2004). Membrane fusion, necessary for the stimulus-coupled release of granule contents, requires that lipid molecules leave their bilayer orientation to merge two lipid bilayers (Cohen and Melikyan, 2004). In neurons, where each vesicle interacts independently with the plasma membrane, exocytosis is coupled to rapid endocytosis and regeneration of SG within milliseconds until seconds. In contrast, mast cells are capable of releasing high amounts of their granular content in response to a single stimulatory event, a process called degranulation, and the regeneration of a granule can take up to $72 \mathrm{~h}$ (Galli et al., 1984; Gandhi and Stevens, 2003; Blank and Rivera, 2004). A resting human intestinal mast cell and a mast cell following activation induced degranulation are shown in Figure 1. Unlike neurons, mast cells SG can form channels by fusing with each other. This so-called compound exocytosis can either occur in a sequential or in a multivesicular manner. In sequential exocytosis, vesicles initially fuse with the plasma membrane followed by the fusion of underlying next vesicles with the first vesicle. In multivesicular exocytosis, vesicles fuse with each other before interacting with the plasma membrane (Alvarez de Toledo and Fernandez, 1990). Compound exocytosis enables mast cells to discharge their contents very efficiently (Pickett and Edwardson, 2006). In response to some stimuli, mast cells show also so-called piecemeal degranulation characterized by gradual loss of granule contents without detectable granule fusion. Thus, piecemeal degranulation allows discharge of discrete packets of granule-associated components without granule exocytosis (Dvorak, 2005). While mast cell mediator release occurs typically, although not exclusively, multi-directionally, other cell types of the immune system such as cytotoxic T cells or natural killer (NK) cells use secretory lysosomes to deliver proteins involved in their effector functions at the immune synapse in a uni-directional, polarized manner. Mast cells also secrete a large variety of inflammatory cytokines, chemokines, and growth factors. Although some of them have been found to be stored in secretory lysosomes secretion of newly synthesized products occurs independently of SG exocytosis. Furthermore, some stimuli like TLR4 ligands or IL-1 induced secretion in the absence of SG release (Kandere-Grzybowska et al., 2003; Qiao et al., 2006).

\section{Resting mast cell}

\section{Activated mast cell}
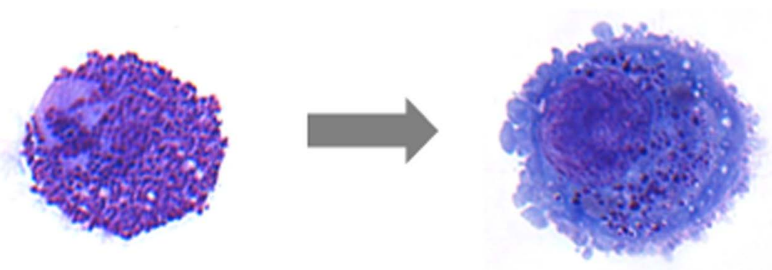

FIGURE 1 | May-Grünwald/Giemsa stain of a resting human intestinal mast cell and a mast cell following activation induced degranulation.

Note the increase in size and loss of granule staining.

\section{SNARE PROTEINS IN DEGRANULATION}

The fusion between vesicles or the plasma membrane is not a spontaneous event. It requires a specific set of proteins called Soluble N-ethylmaleimide-sensitive factor attachment protein receptors (SNAREs) that are highly conserved in all eukaryotes (Sudhof and Rothman, 2009; Sudhof and Rizo, 2011). They were initially discovered by several independent approaches involving yeast genetics and biochemical purification procedures from synaptic membranes and by the ability to bind soluble N-ethylmaleimidesensitive factor (NSF)-attachment proteins, which are adapters that connect the fusion machinery to the NSF ATPase (Novick et al., 1980; Bennett and Scheller, 1993; Sollner et al., 1993). The SNARE machinery of membrane fusion involves different sets of proteins that lie on opposing membranes. They enable fusion by forming a highly stable tetrameric trans-SNARE complex through four conserved 60-70 aa SNARE motifs (Sutton et al., 1998). Dissociation of this complex is the energy-requiring step in fusion and is mediated by the NSF ATPase (Hanson et al., 1997). A typical trans-SNARE complex at the plasma membrane includes a vesicular SNARE ( $v$-SNARE) such as vesicle associated membrane protein (VAMP) that pairs with two target membrane SNAREs (t-SNAREs) such as a Syntaxin (STX) molecule and synaptosomeassociated protein of 23 (ubiquitous) or 25 (neuronal) $\mathrm{kDa}$ (SNAP23/25) containing two SNARE motifs (Sutton et al., 1998). To take into account that $\mathrm{v}$-SNAREs can also be found on the target membrane, for example in the case of homotypic vesicle fusion, SNAREs have also been classified structurally into R-SNAREs (corresponding with few exceptions to $\mathrm{v}$-SNAREs) based on a central $\mathrm{R}$ residue in the 0 layer of the classical four-helix-bundle of the SNARE complex and Q-SNAREs with a central Q residue (Hong, 2005). Trans-SNARE complex, generally consists of either one v-SNARE and two or three t-SNAREs or one R-SNARE and two or three QSNAREs. Figure 2A illustrates SNARE complex formation catalyzing granule fusion in mast cells and Figure $2 \mathbf{B}$ shows the domain structure of these SNAREs and potential phosphorylation sites.

Mast cells express a wide array of SNAREs albeit their localization may differ between different cell types and species. To date, described SNARE proteins in mast cells include the t-SNAREs SNAP-23 as well as STX2, 3, 4, and 6. VAMP family protein members include VAMP2, 3, 4, 7, and 8 (Sander et al., 2008; Benhamou and Blank, 2010). Their functional implication in secretory mechanisms has been partially explored, but not in all cases precise colocalization studies with known marker proteins of mast cell compartments have been performed. The first study demonstrating SNARE-mediated contribution to mast cell degranulation was published in 1998 by the group of D. Castle (Guo et al., 1998). They showed that introduction of antibodies directed to SNAP-23 into permeabilized rat peritoneal mast cells inhibited exocytosis independent of whether it was stimulated through GTP $\gamma S$ or calcium. During exocytosis plasma membrane-localized SNAP-23 relocated into the interior of the cell along degranulation channels in agreement with a compound mode of exocytosis. In another study overexpression of SNAP23 , but not of a derived VAMP-binding mutant, enhanced mast cell exocytosis (Vaidyanathan et al., 2001). Concerning STX family members it was reported in the RBL mast cell line that STX4 


\section{A}

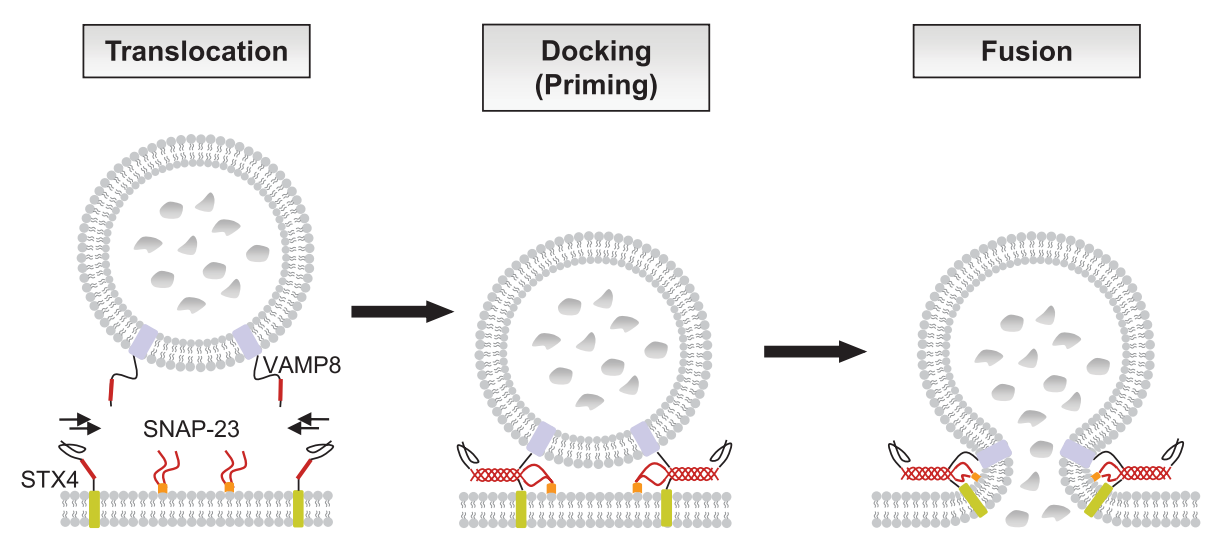

B

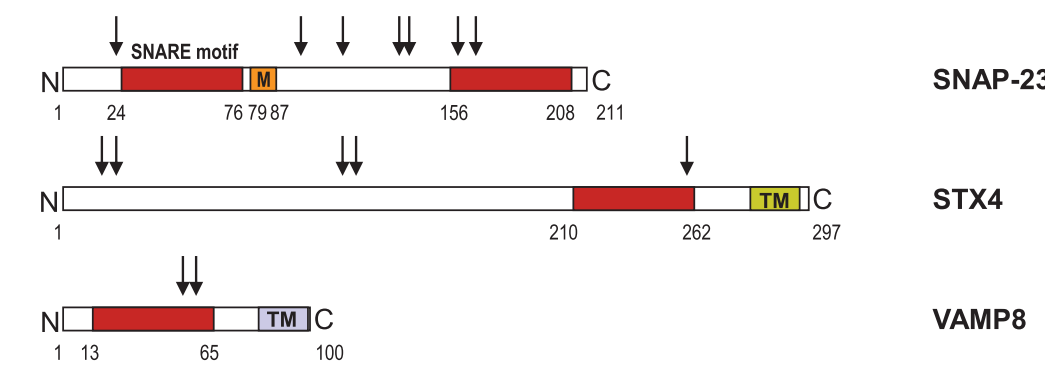

FIGURE 2 | SNARE catalyzed granule fusion in mast cells.

(A) Secretion of mediators requires fusion of vesicle and plasma membranes. Upon activation through $\mathrm{Fc \varepsilon RI}$ secretory granules translocate to and dock at the plasma membrane where the t-SNAREs SNAP-23 and STX4 together with the V-SNARE VAMP8 form stable tetrameric complexes of bundled helices bringing the lipid bilayers into a close distance to catalyze membrane fusion. The SNARE motifs of SNAP-23, STX4, and VAMP8, which become highly organized in the four helical bundle during the formation of the trans-SNARE complex are highlighted in color. (B) The primary structure of human SNAP-23, STX4, and VAMP8 as adapted from Hong (2005) is shown with SNARE motifs for each protein in like colors. STX4 and VAMP8 have C-terminal transmembrane domains (TM), whereas the linker domain of SNAP-23, which connects the two SNARE motifs, has a membrane anchor domain, consisting of palmitoylated cysteine residues (M). Numbers indicate protein or domain boundaries, arrows indicate potential phosphorylation sites (http://www.phosphosite.org). Phosphorylation of mouse SNAP-23 on $\mathrm{Ser}^{95}$ and $\mathrm{Ser}^{120}$ was found to modulate regulated mast cell exocytosis (Hepp et al., 2005), whereas phosphorylation of STX4 was not altered during secretion in RBL cells (Pombo et al., 2001). was recruited to the raft domain during stimulation, where it was able to form enhanced complexes with SNAP-23 (Puri and Roche, 2006). Furthermore, siRNA-mediated knock-down inhibited IgE-mediated degranulation response (Woska and Gillespie, 2011). Similarly, overexpression of STX4 but not STX2 or STX3 inhibited exocytosis (Paumet et al., 2000). Concerning VAMP proteins several recent studies reported a role of VAMP8, a v-SNARE initially named endobrevin (Wong et al., 1998) due to its localization and function in endosomes and endosomal fusion. The latter underlines the close connection between the endocytic and secretory compartments in mast cells. One study (Tiwari et al., 2008) showed that bone marrow-derived mast cells (BMMCs) derived from VAMP8-deficient mice had reduced release of histamine and $\beta$-hexosaminidase while secretion of TNF, CCL2, IL-6, and IL-4 was intact suggesting that VAMP8 acts in pre-stored mediator secretion. The role of VAMP8 was confirmed in vivo, as passive systemic anaphylaxis responses were diminished in VAMP8-deficient animals (Tiwari et al., 2008). Similarly, introduction of a soluble recombinant VAMP8 protein into RBL-2H3 cells markedly inhibited release of $\beta$-hexosaminidase (Lippert et al., 2007). More recently, studies analyzing the secretion from pancreatic acinar cells suggested that VAMP8 may mediate in particular granule-granule fusion as in these cells only secondary, but not primary fusion events were inhibited in vamp 8 knock-out cells (Behrendorff et al., 2011). While this was not particularly studied in mast cells, it was observed that for VAMP8 both colocalization with granule and with plasma membrane markers increased suggesting that VAMP8 may also participate in both types of fusion events (Tiwari et al., 2008). Another study using VAMP8deficient BMMC found that VAMP8 controls release of serotonin, cathepsin- $\mathrm{D}$, and $\beta$-hexosaminidase, but not of histamine, suggesting that the latter may localize to distinct SGs (Puri and Roche, 2008) rejoining older studies that had reported such differential secretion after depletion of the calcium sensor synaptotagmin II (Baram et al., 1999). On the other hand, both histamine and $\beta$ hexosaminidase release were inhibited in BMMC derived from synaptotagmin II-deficient mice (Melicoff et al., 2009). Furthermore, VAMP8 colocalizes with classical SG markers, serotonin, 
and mMCP-6 (tryptase; Tiwari et al., 2008). Concerning human mast cells the response profile was largely overlapping with the situation in rodents although some subtle differences became apparent. Indeed, in human mast cells SNAP-23 and STX4 were shown to represent fusion proteins involved in pre-stored mediator release. This was shown after introduction of blocking antibodies into human intestinal-derived mast cells that had been permeabilized with streptolysin O (Sander et al., 2008). Interestingly, in addition to VAMP8, VAMP7 also seemed to play a role as both anti-VAMP7 and anti-VAMP8 were able to reduce histamine release. This rejoins previous data obtained in neutrophils and eosinophils, where secretion of pre-stored mediators examined was inhibited with anti-VAMP7, but not with anti-VAMP8. Secretion in these cells also involved the t-SNAREs STX4 and SNAP-23. In rodent mast cells contradictory studies have been reported with regard to the implication of VAMP7. While one study did not see consistent inhibition after introduction of soluble recombinant VAMP7 in contrast to VAMP8, another study using siRNAs found that both VAMP7 and VAMP8 siRNAs were able to inhibit IgE-mediated degranulation responses in RBL cells. However, no functional studies using VAMP7-deficient mice (Danglot et al., 2012) have been reported so far. Similarly, little information is available for the mechanisms involved in granule-granule fusion. While initial studies by Guo et al. suggested a relocation mechanism of the plasma membrane SNARE into nascent degranulation channels, it is possible that granule-granule fusion may be mediated by different types of SNARE protein complexes. They may include for example STX3, which has been reported to localize in rodent cells both to SG and the plasma membrane (Hibi et al., 2000; Martin-Verdeaux et al., 2003). An implication of STX3 is also suggested by the role Munc18-2 plays in granule exocytosis (see below) as the latter specifically binds to STX3, but not to STX4 (Martin-Verdeaux et al., 2003).

\section{SNARE PROTEINS IN CYTOKINE/CHEMOKINE SECRETION}

The role of SNARE proteins in the release of de novo synthesized mediators like cytokines or chemokines from mast cells has hardly been analyzed. However, our knowledge is also accumulating thanks to studies performed in other immune cells. For a generalized review the reader is referred to some excellent recent reviews (Huse et al., 2008; Lacy and Stow, 2011). The data so far indicate that chemokine/cytokine secretion does not follow a unique pathway but rather represents a complex machinery of multiple pathways and organelles. In T cells both a polarized directional pathway to the synapse (whisper) involving the t-SNAREs SNAP-23 and STX4 as well as multi-directional pathways (shout) involving STX6 containing vesicles have been described (Huse et al., 2006). The vesicular carriers of the former are tightly coupled to the accompanying microtubular reorganization, while for the latter fusion occurs at multiple sites at the plasma membrane as shown for life imaging of TNF secreting cells in the presence of tumor necrosis factor- $\alpha$-converting enzyme (TACE) inhibitors that prevent the cleavage of the membrane precursors by the metalloproteinase TACE (also called ADAM17) once they have reached the plasma membrane. Many immune cells are also able to store chemokines/cytokines in cytoplasmic storage organelles from where they get mobilized. The first description of granule-pre-stored cytokines stems from Gordon and Galli (1990) in mast cells. They noticed that certain types of mast cells contain high amounts of pre-stored TNF that get rapidly released upon stimulation. The cytoplasmic storage organelles may correspond to classical mediator-containing SG allowing the rapid release together with other inflammatory mediators (Pelletier et al., 1998). Since then many other chemokines/cytokines have been reported to be pre-stored in cytoplasmic vesicles including besides mast cells for example neutrophils and eosinophils (Bjerke et al., 1996; Calafat et al., 1997; Mahmudi-Azer et al., 2000). In eosinophils the release of CCL5 and IL-4 may involve the mechanism of piecemeal degranulation whereby CCL5/IL-4 present in crystalloid granules get mobilized by forming small vesicular carriers transported to the plasma membrane (Lacy and Stow, 2011).

Another major pathway could be the constitutive release that is fed by the increased transcription and translation of chemokines/cytokines in response to a stimulatory event. The prototype mechanism may be the secretion of newly synthesized TNF by macrophages, which is reported to be organized in two steps (Stow et al., 2006, 2009; Lacy and Stow, 2011). First, the fusion of carriers originating from the Golgi complex with recycling endosomes is mediated by the Q-SNARE complex of STX6-STX7-Vtilb with the R-SNARE VAMP3, and second, the membrane fusion of the recycling endosome and the plasma membrane is mediated by the R-SNARE VAMP3 on the recycling endosome by pairing with the STX4-SNAP-23 Q-SNARE complex on the plasma membrane (Pagan et al., 2003; Murray et al., 2005a,b). On the other hand early studies performed in mast cells examining TNF secretion clearly showed the necessity for a stimulatory calcium signal or activation of PKC as addition of selective pharmacological blockers after some time completely arrested secretion despite the fact that TNF had already accumulated within the cell (Baumgartner et al., 1994).

VAMP8 was the first SNARE protein examined for a role in cytokine/chemokine trafficking in mast cells. As already mentioned above, we and others found in BMMC that absence of VAMP8 did not affect secretion of several chemokines or cytokines tested contrasting with some recent data showing an implication of VAMP8 in anaphylatoxin-induced TNF release in macrophages (Tiwari et al., 2008; Pushparaj et al., 2009). For the latter its implication in cytokine release was specific for TNF as IL-1 $\beta$, IL-6, and CCL3 were not affected. In wild-type macrophages, TNF was found to colocalize with VAMP8-positive vesicles, and in VAMP8deficient macrophages, TNF release was inhibited (Tiwari et al., 2008; Pushparaj et al., 2009). Furthermore, VAMP8 has been shown to regulate the release of TNF and $\beta$-hexosaminidase in macrophages triggered by fMLP (Alvarez de Toledo and Fernandez, 1990). In mast cells, TNF did not colocalize with VAMP8containing vesicles, but was rather found to colocalize with a VAMP3 positive compartment in a manner similar to the compartments described for release of TNF into the phagocytotic cup (Tiwari et al., 2008). Given that VAMP3 has been associated with the recycling endosomal compartment this opens the possibility of trafficking through such a compartment prior to release. Interestingly, further studies in human mast cell lines showed that TNF traffics to the membrane, from where it gets re-endocytosed into cytoplasmic granules suggesting that granular localization could 
depend on a specific mechanism of re-endocytosis (Olszewski et al., 2007) although direct sorting via a Mannose phosphate receptor-dependent pathway has also been proposed in rodent mast cells (Olszewski et al., 2006). On the other hand, when analyzing BMMC, we did not see significant granule localization by probing with an antibody detecting endogenously produced TNF and rather found TNF co-localized with VAMP3-containing fractions. Yet, in some isolated cells we were also able to detect TNF in SG. This agrees with previous data showing that in BMMC a small, but detectable fraction $(<10 \%)$ of TNF gets mobilized rapidly being in line with a SG storage mode (Gordon and Galli, 1991). Figure 3 summarizes possible cytokine secretion pathways in mast cells.

More recently we examined the implication of SNARE proteins in chemokines secretion from human intestinal-derived mast cells reported to represent a potent source of many different human chemokines (Feuser et al., 2012). We found that blocking antibodies directed to SNAP-23 and STX3, but not STX2 and VAMP3, inhibited release from all chemokines tested (CXCL8, CCL2, CCL3, and CCL4; Frank et al., 2011). It should be noted that in human mast cells STX3, like STX4, is localized at the plasma membrane, while in rodent mast cells it is found mainly on SG. By contrast a differential behavior was noted concerning other SNARE proteins tested. STX4 and VAMP8 were found to play a specific role in CCL8 secretion while anti-STX6 selectively inhibited CXCL8 and CCL2 and anti-VAMP7 CCL3. Thus, similar to the findings observed in macrophages, the release of de novo synthesized cytokines by mast

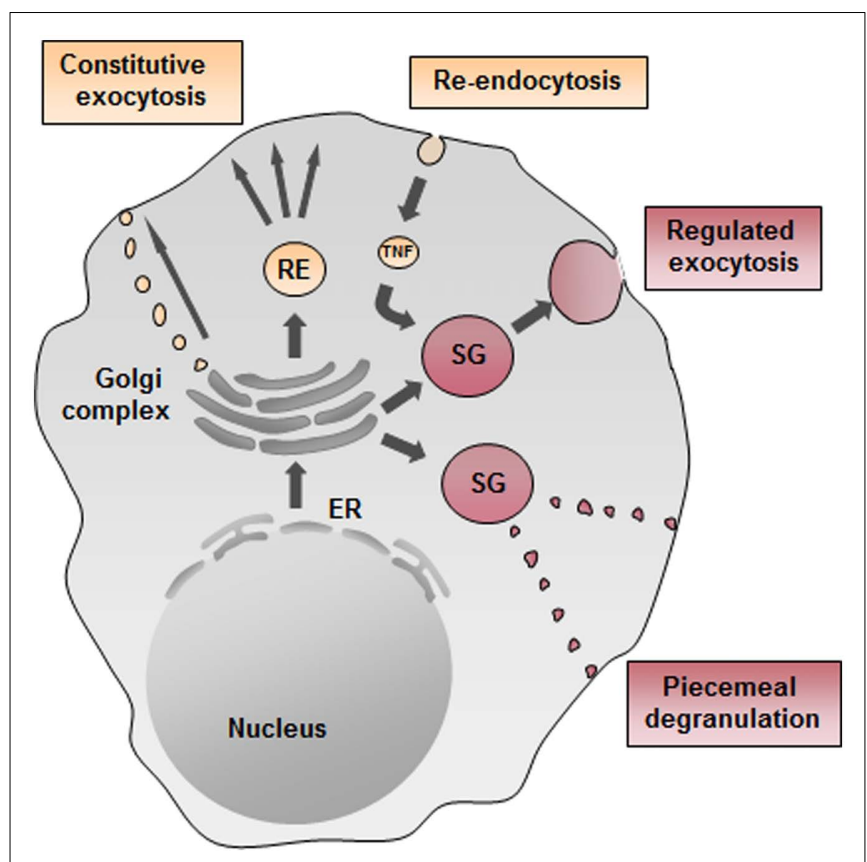

FIGURE 3 | Possible cytokine secretion pathways in mast cells.

Cytokine secretion may occur constitutively through small vesicular carriers or through recycling endosomes (ER) as described for TNF in macrophages. Moreover, TNF could get re-endocytosed from the plasma membrane and transported into secretory granules (SG) and then rapidly released upon stimulation. Another possible pathway of regulated exocytosis in mast cells may be piecemeal degranulation as reported for eosinophils. cells seems to involve more than three or four SNARE proteins. Although the situation concerning exocytosis is in principle different in mast cells and macrophages, the release of cytokines could be similarly organized. In human mast cells chemokine release could be mediated by a Q-SNARE complex consisting of SNAP-23, STX3, or STX4 and the R-SNARE VAMP7 or VAMP8 at the plasma membrane. A second composition could involve a Q-SNARE complex consisting of Vtilb and STX6 together with STX3 or STX4. However, we found that VAMP8 is involved at least in the release of CXCL8 by human mast cells, whereas VAMP3 surprisingly was not involved in any release (Sander et al., 2008; Frank et al., 2011). In summary, our data suggest that vesicular carriers involved in chemokine secretion show a highly heterogenous profile that needs to be further characterized.

\section{MUNC18 PROTEINS IN THE REGULATION OF EXOCYTOSIS}

In contrast to SNARE proteins, less information is available concerning the function of Sec1/Munc18 (SM) proteins known to play fundamental roles in various intracellular secretory trafficking steps (Sudhof and Rothman, 2009). Sec1 mutant yeast cells have been initially identified in a genetic screen in yeast aiming to identify proteins involved in the secretory pathway (Novick et al., 1980). A defect in neurotransmitter release was also apparent for the uncoordinated 18 (unc18) ortholog in nematodes (Hosono et al., 1992) and the drosophila Rop protein (Harrison et al., 1994). SM proteins contain seven family members in humans that bind to STX SNAREs (Bock et al., 2001). Three family members are mammalian uncoordinated18 (Munc18) proteins that are more specifically implicated in regulated exocytosis. They include Munc18-1 (sometimes also called Munc18a; Figure 4A), which is largely expressed in neurons and two ubiquitously expressed isoforms Munc18-2 (Munc18b) and Munc18-3 (Munc18c). They show specificity of binding for certain STX family members. Thus, Munc18-1 can interact with STX1, 2, and 3, Munc18-2 with STX1, 3, and slightly with STX2 (Hata and Südhof, 1995); Munc18-3 interacts with STX2 and 4 and to a lesser extent with STX1 (Tellam et al., 1995). Recently, Munc18-2 was also shown to interact with STX11 (Cote et al., 2009). Studies in knock-out mice have clearly underlined the important role of Munc18 proteins in regulated exocytosis. Animals deficient in Munc18-1 have a complete block of neurotransmission and mice die at birth due to a breathing defect (Verhage et al., 2000). Mice deficient in Munc18-3 are early embryonic lethal and in the heterozygous stage are glucose intolerant after receiving high-fat-diet due to a secretion defect in insulin-producing pancreatic beta cells (Oh et al., 2005). On the other hand, externalization of GLUT4 at the cell surface was enhanced in munc18-3 knock-out adipocytes at low concentration of insulin (Kanda et al., 2005). The reported essential role of Munc18 proteins in the secretory pathway was initially difficult to explain as biochemical experiments as well as crystal structure analysis of the STX1/Munc18-1 complex showed that Munc18 binding to their respective STX partners blocked the interaction with other SNAREs rather arguing for a negative regulatory function (Araki et al., 1997; Misura et al., 2000). This problem was solved by the discovery that Munc18-1 in addition of binding to the closed conformation of STX1 was also able to bind to the assembled tetrameric SNARE complex (Sudhof and Rothman, 2009). 
A

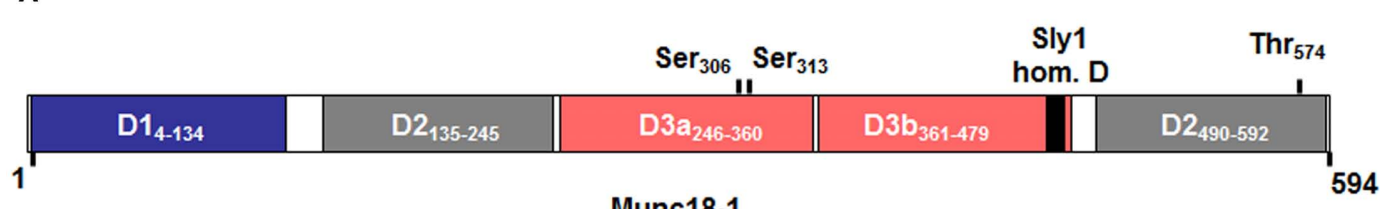

Munc18-1

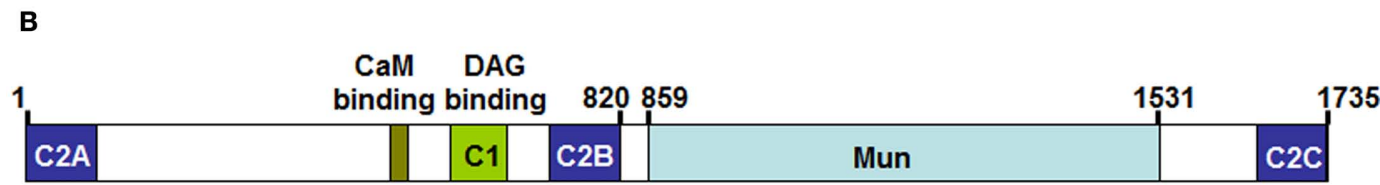

Munc13-1

FIGURE 4 | Domain structure of Munc18-1 (A) and Munc13-1 (B) as adapted from Koch et al. (2000); Misura et al. (2000); Li et al. (2011). Numbers above indicate protein or domain boundaries. For Munc18-1 domain boundaries are also directly included in the inset. The Munc18-1 protein contains three domains (with domain 3 being divided in D3a and D3b). According to crystal structure analysis the molecule adopts a horseshoe like structure that holds the STX-bound molecule in its closed conformation. Contact surfaces reside in D1 and D3a, which form the bottom ends of the horseshoe, while D2 and D3b form the upper end. Domain 3b includes the so-called Sly 1 homology domain containing the residue homologous to the Sly1-20 mutant in the yeast Sly1 protein, which bypasses the requirement for a Rab effector protein in yeast vesicular transport (Dascher et al., 1991). Above the domains are also indicated protein kinase $\mathrm{C}\left(\mathrm{Ser}^{306}\right.$ and $\left.\mathrm{Ser}^{313}\right)$ and Cyclin dependent kinase (Thr ${ }^{574}$ ) phosphorylation sites that may regulate Munc18-1 effector functions. (B) The Munc13-1 protein contains several calcium-binding C2 domains, a Diacylglycerol (DAG) C1 domain making it responsive to stimulation with PKC as well as a calmodulin binding domain. Note that the ubiquitouisly expressed isoform 13-4, which is important in mast cell exocytosis lacks the $\mathrm{N}$-terminal $\mathrm{C} 2 \mathrm{a}, \mathrm{CaMb}$, and $\mathrm{C} 1$ domains. The Mun domain shows structural similarity to thethering proteins and may play a role in the transition of the closed conformation of STX molecules by contacting either Munc18 or STX molecules (Li et al., 2011; Sudhof and Rizo, 2011).
It was proposed that Munc18-1 switches its binding mode during the Munc13-regulated (see below) conformational transition of Syntaxin proteins to their "open" form that allows engagement with other SNARE partners (Sudhof and Rizo, 2011). Once the transition completed Munc18 directly participates in the fusion reaction. Phosphorylation events mediated by protein kinase $\mathrm{C}$ shown to phosphorylate $\operatorname{Ser}^{316}$ and $\operatorname{Ser}^{313}$ in Munc18-1 as well as cyclin dependent kinase phosphorylating $\mathrm{Thr}^{574}$ (Figure 4A) may also participate in such regulatory events (Fletcher et al., 1999; Snyder et al., 2006; Wierda et al., 2007). The fusion enhancing role of Munc18 was directly demonstrated in biochemical reconstitution experiments (Shen et al., 2007). Furthermore, structural data showed that Munc18-1 binds the assembled SNARE complex at the C-terminal end close to membranes suggesting that Munc18 might cooperate with the SNARE complex by providing a supplementary pulling force (Carr and Rizo, 2010). Nevertheless, its physiological function may even be more complex as Munc18 proteins may promote fusion also by other mechanism that may relate to their ability to interact with other fusion regulatory proteins such as Mints (Ho et al., 2006), Doc2 (Higashio et al., 2008), Granuphilin (Fukuda et al., 2005), or Cab45 (Lam et al., 2007). Besides promotion of fusion it has been reported that Munc18 proteins also regulate steps such as vesicle translocation, vesicle tethering and vesicle docking (Burgoyne et al., 2009).

Mast cells were found to express the ubiquitous isoforms Munc18-2 and Munc18-3 (Martin-Verdeaux et al., 2003). The neuronal isoform Munc18-1 has also been detected, however, so far only at the mRNA level (Nigam et al., 2005). In coimmunoprecipitation experiments Munc18-2 interacted with STX3 and less so with STX2, while Munc18-3 interacted with STX4 (Martin-Verdeaux et al., 2003). Interestingly, in contrast to the neuronal isoform, Munc18-2 was found to be localized to SG, which is, however, in agreement with the granular localization of its STX3 binding partner (Figure 5). Munc18-3 was localized at the plasma membrane in agreement with the plasma membrane localization of its binding partner STX4. Functional studies have so far revealed only a role for Munc18-2. Expression of peptides corresponding to an activation loop or overexpression of wild-type proteins in RBL cells was able to inhibit regulated exocytosis (Martin-Verdeaux et al., 2003). By contrast, no biological function was shown after expression of corresponding peptides or proteins of Munc18-3. Recent studies using a siRNA-mediated knock-down of Munc18-2 also blocked inflammatory mediator secretion in RBL mast cells (Tadokoro et al., 2007). The mechanism of action has not been investigated. Yet it was interesting to note that in the presence of microtubule-depolymerizing agents one could observe a redistribution of Munc18-2 from secretory vesicles to the cytoplasm, indicating a connection with the microtubule cytoskeleton (Martin-Verdeaux et al., 2003). In that respect, neuronal Munc18-1 co-purified and co-localized with cytoskeletal proteins such as $\alpha$ and $\beta$ tubulin (Bhaskar et al., 2004). New data also show a coupling of STX1/Munc18-1 to the microtubule motor protein Kinesin via the FEZ1 adaptor protein further confirming the tight connection of Munc18-1 with this cytoskeletal compartment (Chua et al., 2012). Munc18 isoforms have also been shown to function in other immune cells. In neutrophils, Munc18-2 could act as a regulator of primary granule exocytosis, while Munc18-3 may preferentially regulate the fusion of secondary/tertiary granules. Recently, human familial hemophagocytic lymphohistiocytosis type 5 (FHL-5) patients were shown to contain mutations within Munc18-2 that led to a deficiency in expression of Munc182 and concomitantly STX11 (Cote et al., 2009; Zur Stadt et al., 


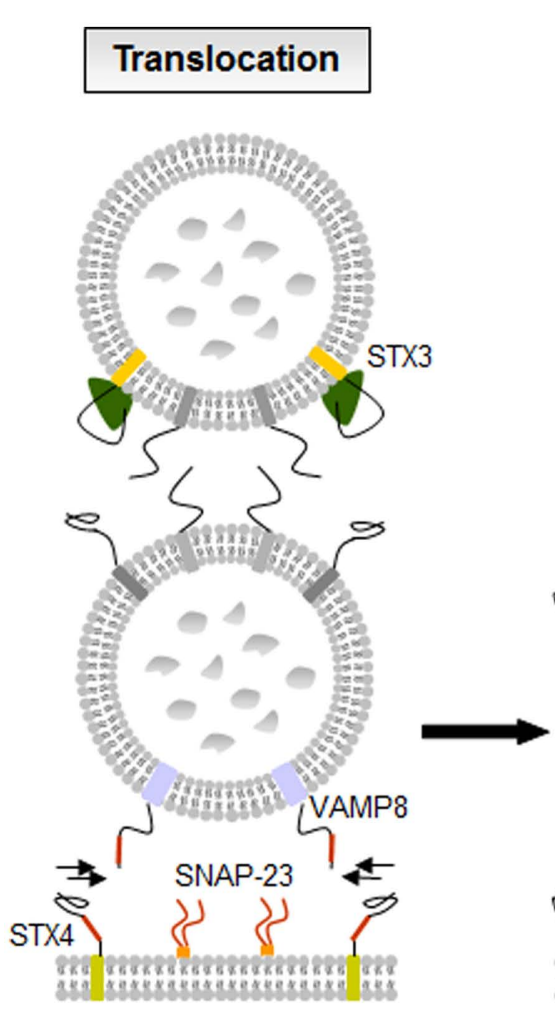

Munc18-2
Munc13-4 Rab27
Docking (Priming)
Fusion

Complexin II

Synaptotagmin II

SCAMP

FIGURE 5 |The fusion machinery in mast cell secretion. In resting cells membrane fusion is blocked likely by molecules such as STX3-bound

Munc18-2. Upon activation through Fc\&RI secretory granules translocate to and dock at the plasma membrane where the SNARE proteins assemble into tetrameric complexes. Multiple accessory proteins such as Munc18-2,
Munc13-4, Rab27, Doc2 $\alpha$, complexin II, synaptotagmin II, or SCAMPs, are involved as "gatekeepers" of the fusion reaction holding effectors in an inactive state, as tethering factors controlling docking and priming, or as regulators of the SNARE complexes triggering the calcium-dependent membrane fusion.
2009). Like in FHL4 patients, who have mutations in STX11 (Zur Stadt et al., 2005), this caused lytic granule exocytosis in NK and cytotoxic T cells, albeit the phenotype was largely dependent on the type of mutation.

\section{MUNC13 PROTEINS IN REGULATED EXOCYTOSIS}

In addition to SNARE and SM proteins, Munc13 protein family members have also been demonstrated to play an essential role in vesicle fusion where they are thought to be involved in vesicle priming. Munc13 are large active zone proteins containing multiple domains (Figure 4B) including phospholipids and calcium-binding $\mathrm{C} 2$ domains, a phorbol ester binding $\mathrm{C} 1$ domain, and a large Mun domain homologous with tethering factors (Koch et al., 2000; Li et al., 2011; Sudhof and Rizo, 2011). Genetic ablation of neuronal isoforms (Munc13-1, -2, and -3) in mice or the C. elegans homolog unc-13 led to severe defects in both spontaneous and evoked synaptic transmission due to a defect in vesicle priming (Augustin et al., 2001; Rosenmund et al., 2002). Similarly, mutations in the ubiquitously expressed Munc13-4 isoform showed that granules in cytotoxic $\mathrm{T}$ cells although appear to dock do not fuse leading to type 3 familial hemophagocytic lymphohistiocytosis (FLH3; Feldmann et al., 2003). The fact that priming defects could be rescued with a STX1 mutant promoting a constitutively “open” form of STX1 (Richmond et al., 2001) suggested that Munc13 isoforms are involved in the transition of the closed form of STX to its open form that also allows Munc18-1 to adapt its transition to the new binding mode able to bind the assembled trans-SNARE complex. This function was confirmed using NMR and fluorescence spectroscopic as well as crystal structural studies (Li et al., 2011; Ma et al., 2011). Recruitment of Munc13 to the membrane and fusion machinery may be mediated by its capacity to interact with Rab proteins such as Rab3 for neuronal-expressed Munc13 isoforms or Rab27a in cytotoxic T cells (Menager et al., 2007). Indeed, recent studies identified in Munc13-4 a region at the C-terminal end of its first C2A domain involved in Rab27a binding (Elstak et al., 2011). This domain was required in order for Munc13-4 to support degranulation notably by restricting the motility and by securing the tight docking of SG at the plasma membrane. Studies in cytotoxic $\mathrm{T}$ cells showed that in addition to its role as a priming factor Munc13-4 also promotes the fusion of late endosomes with recycling endosomes to form secretion-competent secretory vesicles indicating additional roles for this protein (Menager et al., 2007). 
Concerning mast cells, several studies indicated that like in cytotoxic T cells Munc13-4 has important functions. Indeed, both Munc13-4 and Rab27 isoforms Rab27A and Rab27B are highly expressed in mast cells and both proteins were shown to interact (Neeft et al., 2005). Overexpression of Munc13-4 enhanced degranulation indicating a positive regulatory function. In agreement siRNA-mediated knock-down inhibited degranulation and transfection with wild-type, but not Rab27-deficient binding mutants could rescue the inhibitory phenotype (Elstak et al., 2011). This indicates that like in cytotoxic T cells Munc13-4 could promote fusion by stabilizing docked vesicles at the plasma membrane. In addition to Rab27 isoforms, Munc13-4 was also shown to interact with the calcium and phospholipids-binding C2 domain containing effector Doc $2 \alpha$ in mast cells (Higashio et al., 2008). Doc2 $\alpha$ interacts with Munc13-4 via two distinct $\mathrm{N}$ - and C-terminal located regions (Higashio et al., 2008). The importance of Doc $2 \alpha$ is underlined by the marked inhibition of exocytosis in Doc $2 \alpha$-deficient BMMC (Higashio et al., 2008). Furthermore, expression of mutants lacking the Munc13-4 interacting domains impaired secretion after transfection. These mutants were also unable to rescue secretion after siRNA-mediated knock-down of Doc $2 \alpha$ in contrast to wild-type Doc $2 \alpha$. Taken together, these results support an important role of Munc13-4 in mast cell degranulation. Munc13-4 likely acts together with other fusion accessory proteins such as Rab27 isoforms and Doc $2 \alpha$ to stabilize vesicle docking and prime them for fusion (Figure 5). The latter could in part be dependent on its ability to catalyze the transition of the STX/Munc18 complex to an "open" conformation ready to engage with other SNARE partners.

\section{ROLE OF OTHER ACCESSORY PROTEINS IN THE REGULATION OF EXOCYTOSIS}

Since it has been realized that there must be other factors for a complete and fast vesicle fusion apart from SNARE proteins, a long list of other accessory regulators such as Rab GTPases, complexins, synaptotagmins, or secretory carrier membrane proteins (SCAMPs) were found in addition to SM and Munc13 proteins.

Rab GTPases are low-molecular-weight GTPases, which function as molecular switches that alternate between two conformational states: the GTP-bound "on" form and the GDP-bound "off” form (Stenmark, 2009). Rab GTPases are reversibly associated with membranes and involved in regulating membrane traffic. More than 70 Rab proteins have been identified in mammalian cells up to now (Hutagalung and Novick, 2011). Mast cells express different members of the Rab3 and Rab27 family. RBL-2H3 mast cells were found to express Rab3 isoforms with Rab3D being the most prevalent (Roa et al., 1997; Tuvim et al., 1999). Moreover, Rab3D was found to localize on mast cell SG and to translocate to the plasma membrane upon exocytosis suggesting that Rab3D is a component of the regulated exocytosis in mast cells (Tuvim et al., 1999). Maybe, it is involved in controlling SNARE assembly in a calcium-dependent manner (Pombo et al., 2001). However, mast cell secretion in rab3d knock-out mice was unaffected, although compensatory mechanisms by other isoforms have not been investigated (Riedel et al., 2002).

Murine BMMCs express both Rab27a and Rab27b isoforms, which localize to SG (Mizuno et al., 2007; Figure 5). Rab27a and its effector Munc13-4 were described to be involved in exocytosis in RBL-2H3 cells (Goishi et al., 2004; Neeft et al., 2005). The Munc13-4-Rab27a complex has been identified to be required for tethering of secretory lysosomes to the plasma membrane and controlling their docking that is necessary for degranulation in immune cells (Elstak et al., 2011). However, secretory defects were only present in rab27b knock-out and rab27a/rab27b double knock-out mice, but not in rab27a knock-out mice (Mizuno et al., 2007). Immunofluorescence studies indicate that a subset of Rab27b-deficient BMMCs exhibit mild clustering of granules. Double Rab27-deficient BMMCs showed almost 10-fold increase of granules in microtubule-dependent movement suggesting that Rab27 proteins, particularly Rab27b, regulate the transition from microtubule to actin-based motility and are crucial for mast cell degranulation (Mizuno et al., 2007).

Complexin I and II are small soluble cytosolic proteins and interact with SNARE complexes (Sudhof and Rothman, 2009). Knock-out mice showed reduced neurotransmitter release suggesting that complexin acts as a positive regulator of exocytosis (Reim et al., 2001). On the other side, injection or overexpression of complexin reduced neurotransmitter or exocytotic release and injection of anti-complexin antibodies stimulated neurotransmitter release suggesting that complexin is a negative regulator (Ono et al., 1998; Itakura et al., 1999). In neuronal synapses, complexin was found to simultaneously suppress spontaneous fusion and activate fast calcium-evoked fusion. The dual-function was dependent on SNARE binding and N-terminal sequences of complexin that localize to the point where SNARE complexes insert into the fusing membranes, suggesting that complexin controls the force that SNARE complexes apply onto the fusing membranes (Maximov et al., 2009).

RBL-2H3 cells express complexin II, but not complexin I (Tadokoro et al., 2005). Complexin II knock-down experiments revealed that complexin II positively regulated exocytotic release in mast cells by translocating to the plasma membrane and enhancing the calcium sensitivity of the fusion machinery (Tadokoro et al., 2005). The association of complexin II with SNARE complex (Figure 5) was not sufficient to trigger exocytotic membrane fusion. In vitro binding assays showed that complexin II interacts with SNARE complex containing STX3 to regulate mast cell degranulation, but does not bind to SNARE complex containing STX4 (Tadokoro et al., 2005). STX3 is found on the plasma membrane as well as on SG and thus might be involved in both the fusion with the plasma membrane and granule-granule fusion to facilitate exocytotic release in mast cells (Hibi et al., 2000; Martin-Verdeaux et al., 2003; Tadokoro et al., 2007, 2010). The calcium sensor synaptotagmin is thought to finally trigger membrane fusion by reversing the complexin block on activated SNARE complexes in addition to its calcium-dependent phospholipid-binding activity (Maximov et al., 2009).

Synaptotagmins are calcium-binding proteins containing two conserved binding domains at their C-terminus, $\mathrm{C} 2 \mathrm{~A}$ and $\mathrm{C} 2 \mathrm{~B}$, and a single $\mathrm{N}$-terminal transmembrane domain anchored to membranes of secretory vesicles (Sudhof, 2004). The binding of calcium to the $\mathrm{C} 2$ domains alters their electrostatic surface charge and mediates most of the calcium-dependent functions of synaptotagmin (Chapman, 2008). It is thought that synaptotagmin 
triggers fusion by binding to SNARE complexes on the target membrane with its $\mathrm{C} 2 \mathrm{~A}$ domain and undergoes calcium-dependent self-oligomerization of its $\mathrm{C} 2 \mathrm{~B}$ domain, accompanied by interaction with negatively charged membrane phospholipids. SNAREs are able to form complexes in the absence of calcium, but the arrangement by synaptotagmin in response to calcium is essential for the fusion event (Chapman, 2008).

Several isoforms of synaptotagmin such as synaptotagmin II, III, V, or IX are expressed in mast cells (Baram et al., 2001; Haberman et al., 2007). Synaptotagmin II was identified as the major isoform expressed in RBL-2H3 cells (Baram et al., 1999) and found to regulate exocytosis but not other secretory responses of mast cells (Melicoff et al., 2009; Figure 5). Synaptotagmin IIdeficient mice had normal mast cells in number, morphology, and structure or storage of granule contents. BMMCs generated from these mutant mice had no defects in IgE-dependent generation and secretion of cytokines and eicosanoids, but had a marked deficiency in the exocytosis of their pre-formed granule mediators (Melicoff et al., 2009). Using a liposome-based fusion assay it was shown that synaptotagmin II regulates membrane fusion of SNARE-containing liposomes, and that this regulation is dependent on synaptotagmin II concentration, $\mathrm{Ca}^{2+}$, and phosphatidylserine (Nagai et al., 2011). Synaptotagmin III has been found to be required for the formation of the endocytic recycling compartment (ERC), which is involved in sorting of proteins from SG and connecting the endocytic pathway with the exocytic one (Sagi-Eisenberg, 2007). Synaptotagmin IX was found to be endogenously expressed and ERC-localized in mast cells (Haberman et al., 2003, 2005). Knock-down of synaptotagmin IX was associated with mistargeting of TGN38, a protein that normally cycles between the trans-Golgi network, the ERC, and the plasma membrane, and its delivery to the SG. Thus, synaptotagmin IX is a part of the machinery that is involved in the formation of transport carriers that mediate SG protein sorting (Haberman et al., 2007).

Secretory carrier membrane proteins are conserved four transmembrane-spanning proteins associated with recycling vesicular carriers. Five distinct SCAMPs have been reported in mammals with SCAMPs 1-3 being expressed in mast cells (Castle et al., 2002). SCAMP1 and 2, the most prevalent SCAMPs in mast cells, are present in SG membranes and other intracellular membranes. A small population was found to partially colocalize with SNAP-23 and STX4 (Guo et al., 2002). Administration of the E peptide, an oligopeptide within the cytoplasmic segment linking the second and third transmembrane spans, particularly of SCAMP2, potently inhibits exocytosis in streptolysin O-permeabilized mast cells. It blocks fusion beyond the docking step where granules contact the cell surface and each other during compound exocytosis suggesting that SCAMP2 may play a critical role in completing exocytosis (Guo et al., 2002; Figure 5). SCAMPs may also act at a step to form fusion pores because in neuroendocrine PC12 cells SCAMP2 interacts with Arf6 and Phospholipase D1 coupling Arf6-stimulated PLD activity to the exocytotic fusion pore formation (Liu et al., 2002). Table 1 summarizes SNAREs and accessory proteins found in mast cells.

\section{THE FUSION MACHINERY AND CELL SIGNALING}

Many, if not all proteins of the membrane fusion machinery contain sequences amenable to post-translational modifications such as phosphorylation, lipid modifications, and nitrosylation. These events have been shown to be involved in the regulation of SNARE complex formation connecting it to cell signaling (Matsushita et al., 2003; Snyder et al., 2006; Davletov et al., 2007). One important example in mast cells is the phosphorylation of the t-SNARE protein SNAP-23 that had been shown to be critically involved in the regulation of fusion. Indeed, a sizable fraction (10\%) of SNAP-23 becomes transiently phosphorylated during degranulation on $\mathrm{Ser}^{95} / \mathrm{Ser}^{120}$ within its cysteine-rich linker region (Hepp et al., 2005; Figure 2B). Interestingly, this involved Ikappa B kinase 2 (IKK2), an enzyme previously known to regulate nuclear translocation of the NF- $\kappa \mathrm{B}$ transcription factor through the phosphorylating cytoplasmic inhibitor IkB (Suzuki and Verma, 2008). Indeed, IKK2-deficient mast cells showed a strong impairment of their capacity to degranulate and mediate anaphylactic responses in vivo. This was independent of their capacity to activate NF-кB and could be rescued in the presence of a phosphomimetic mutant of SNAP-23, while wild-type SNAP-23 was ineffective. Furthermore, in agreement with the demonstration that phosphorylated SNAP-23 was present in enhanced amounts in SNARE complexes, IKK2 was recruited to lipid raft domains, which are the sites of membrane fusion in mast cells. Secretion by mast cells is also regulated by $\mathrm{PKC}$. In particular, BMMC deficient in the calciumdependent isoform PKC $\beta$ are strongly impaired in their capacity to degranulate (Nechushtan et al., 2000). However, the precise molecular targets remain unknown. In addition to kinases, phosphatases were also shown to regulate components of the fusion machinery. Thus, megakaryocyte cytosolic protein tyrosine phosphatase 2 (MEG2) has been described to dephosphorylate NSF on a key tyrosine residue (Huynh et al., 2004). In RBL mast cells MEG2 localized to SG and its overexpression resulted in the formation of large granules (Wang et al., 2002).

Many of the proteins of the fusion machinery also contain domains responding to calcium, one of the most widely used second messengers in cell signaling. Prominent calcium sensors of exocytosis are the synaptotagmin family of proteins. Upon calcium binding to its two tandem C2 domains, neuronal-expressed synaptotagmin I has been shown to undergo an electrostatic switch that promotes oligomerization and phospholipid-binding. This promotes the interaction with membrane lipids causing membrane bending, which facilitates fusion (Chapman, 2008). A similar action was proposed for Doc $2 \alpha$, which also contains two tandem C2 domains. Due to its different calcium binding characteristics and affinity the latter was involved in the asynchronous release, which is less tightly coupled to the action potential (Yao et al., 2011). Both types of sensors are expressed in mast cells and thus likely couple vesicle release to calcium signaling, albeit the mechanisms and connections between these effectors, calcium regulation and the SNARE fusion machinery needs to be studied in detail. Another calcium-regulated activity is Rak3D, a kinase associated with the small GTPase Rab3D (Pombo et al., 2001; Coppola et al., 2002). In vitro, Rak3D was able to phosphorylate STX4, but not STX2 and STX3, thereby decreasing its capacity to interact with 


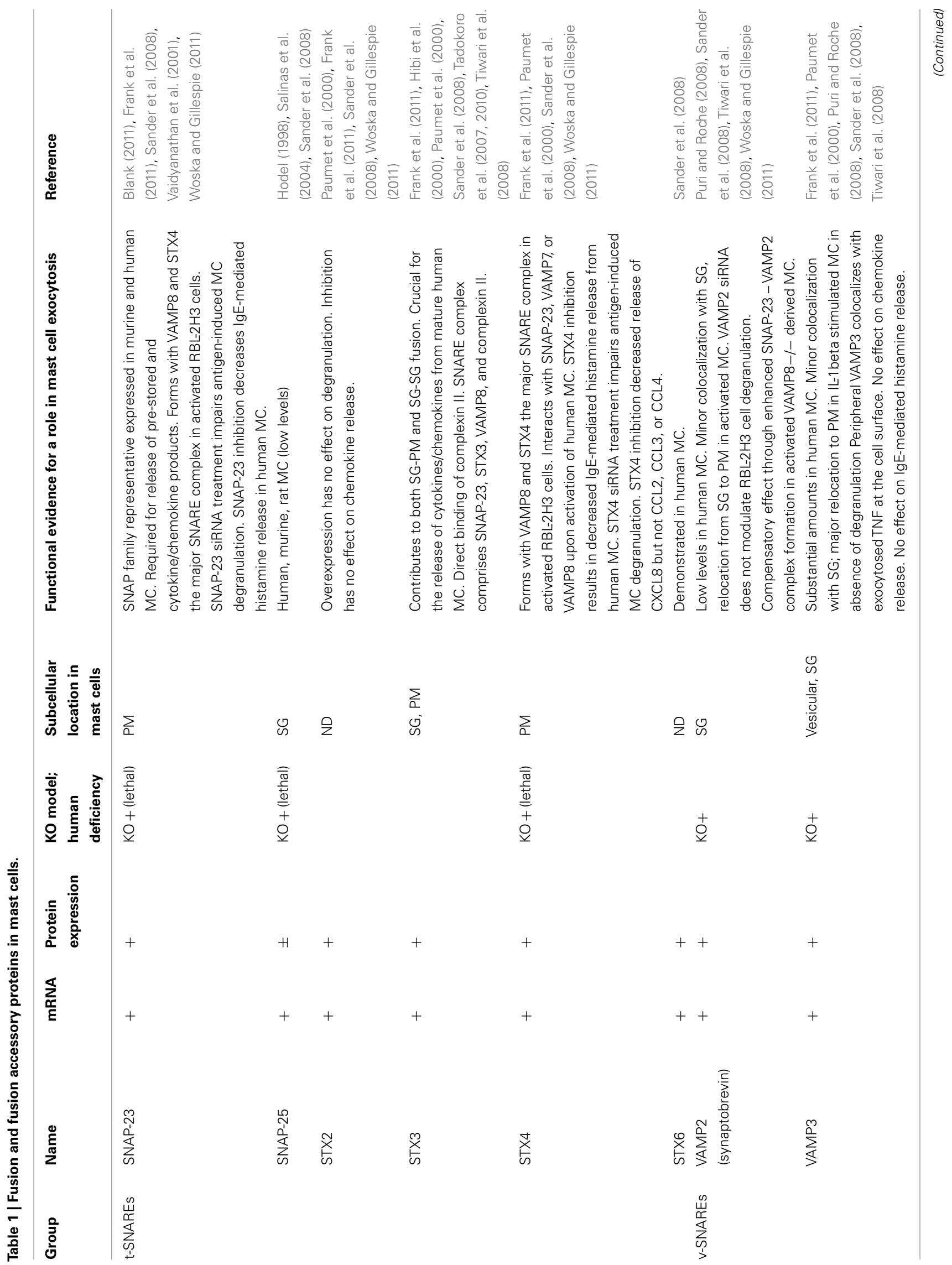




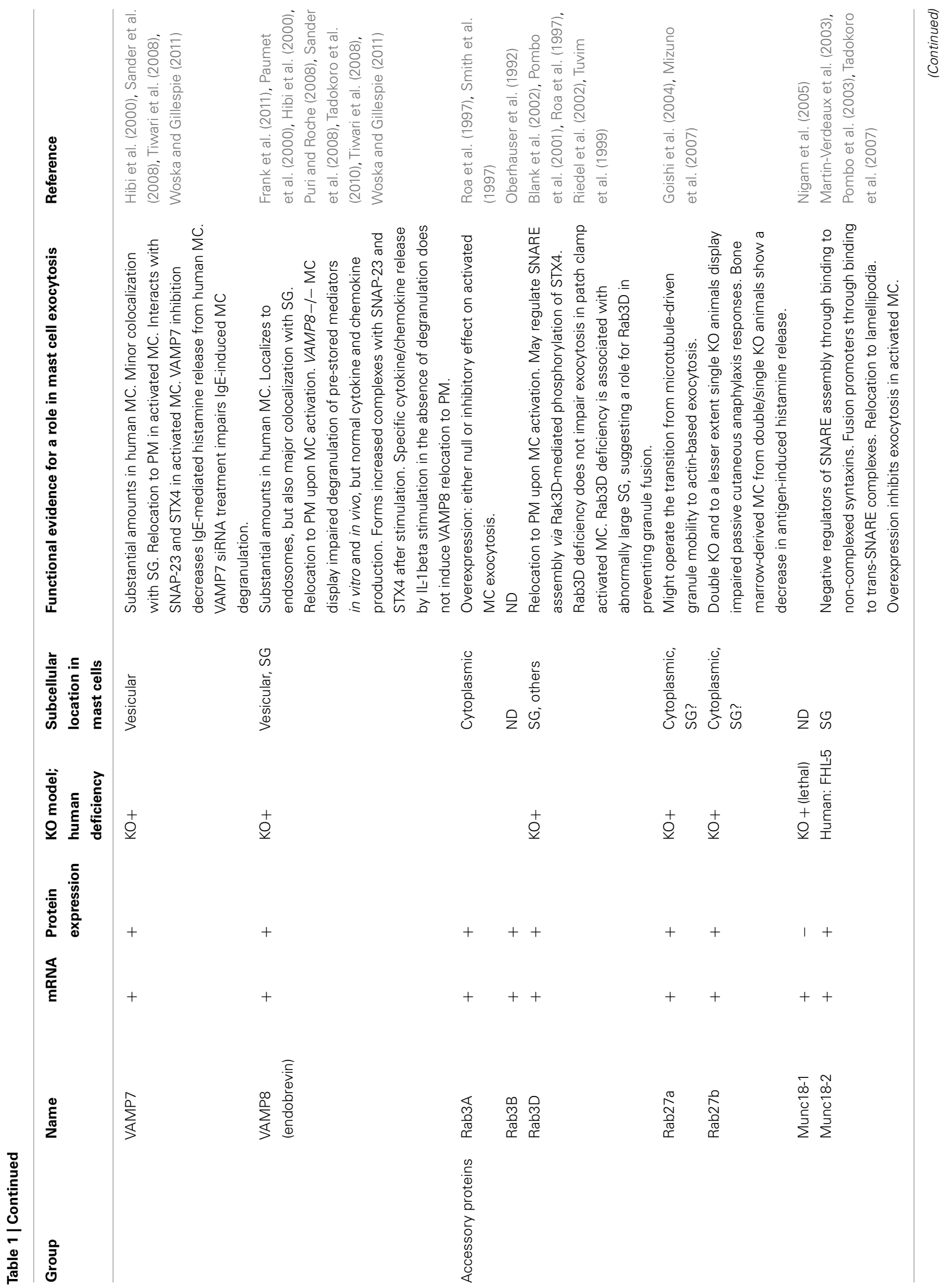




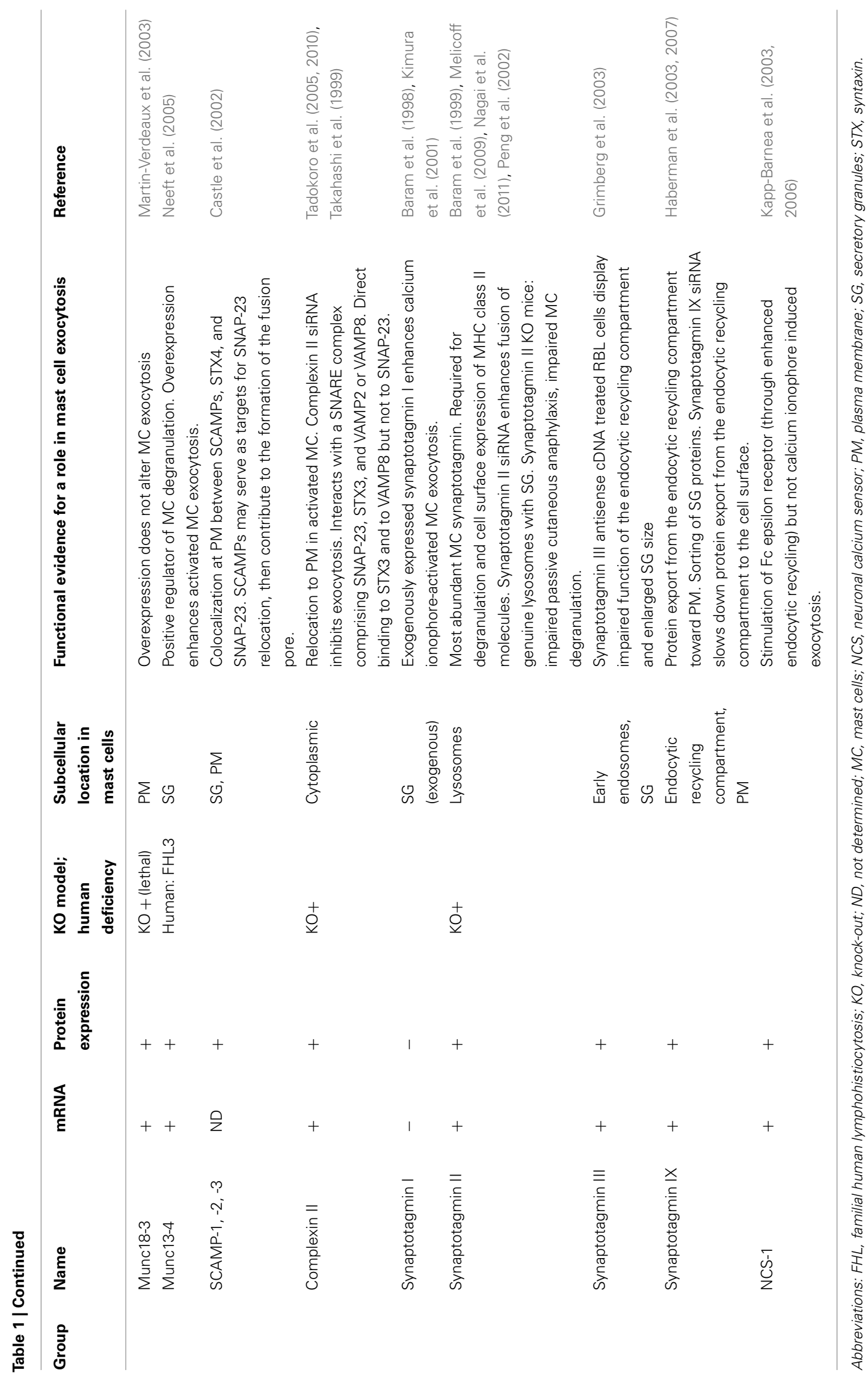


SNAP-23. Rak3D was calcium-regulated as stimulation promoted the disappearance of the activity in Rab3D immunoprecipitates.

Taken together, the SNARE fusion machinery is tightly coupled to cell signaling. This coupling enables the activation, the fine tuning as well as the arrest of fusion events in a tightly regulated manner, which is necessary for appropriate secretory responses. It also integrates the signals from many different receptors able to induce stimulus-secretion coupling.

\section{CONCLUDING REMARKS}

It has now become clear that mast cells use a highly sophisticated machinery of proteins that enable the fusion of vesicles containing pre-stored and newly synthesized inflammatory mediators (Figure 5). Central to this machinery are SNARE proteins able to assemble into a tetrameric complex (Figure 2) that catalyzes the fusion of membranes of different cellular compartments. Although some of the central SNARE proteins involved in mast cell secretory events have been defined, gaps still persist in our understanding of the membrane fusion process. In particular, functional studies showed that the absence of one SNARE protein does not necessarily result in a complete block of exocytosis suggesting that some of its components are redundant. This is also supported by data showing that human mast cells use several types of v-SNARE proteins and that quality and quantity of detectable SNARE complexes is altered in knock-out cells. In addition, it has been known for many years that mast cells undergo compound exocytosis implying also fusion between granules. Although this could imply relocalization of plasma membrane SNAREs into the cell interior it cannot be excluded that different types of SNARE complexes are involved in this process. In agreement, preliminary data in our lab suggest that besides STX4, granule-localized STX3 may also play a role in the fusion process. Furthermore, little is still known about

\section{REFERENCES}

Abraham, S. N., and St John, A. L. (2010). Mast cell-orchestrated immunity to pathogens. Nat. Rev. Immunol. 10, 440-452.

Alvarez de Toledo, G., and Fernandez, J. (1990). Compound versus multigranular exocytosis in peritoneal cells. J. Gen. Physiol. 95, 397-402.

Araki, S., Tamori, Y., Kawanishi, M., Shinoda, H., Masugi, J., Mori, H., Niki, T., Okazawa, H., Kubota, T., and Kasuga, M. (1997). Inhibition of the binding of SNAP-23 to syntaxin 4 by Munc18c. Biochem. Biophys. Res. Commun. 234, 257-262.

Augustin, I., Korte, S., Rickmann, M., Kretzschmar, H. A., Sudhof, T. C., Herms, J. W., and Brose, N. (2001). The cerebellum-specific Munc13 isoform Munc13-3 regulates cerebellar synaptic transmission and motor learning in mice. J. Neurosci. 21, 10-17.

Baram, D., Adachi, R., Medalia, O., Tuvim, M., Dickey, B. F., Mekori, Y. A., and Sagi-Eisenberg, R. (1999).
Synaptotagmin II negatively regulates Ca2+ -triggered exocytosis of lysosomes in mast cells. J. Exp. Med. 189, 1649-1658.

Baram, D., Linial, M., Mekori, Y. A., and Sagi-Eisenberg, R. (1998). Ca2+ dependent exocytosis in mast cells is stimulated by the $\mathrm{Ca} 2+$ sensor, synaptotagmin I. J. Immunol. 161, 5120-5123.

Baram, D., Mekori, Y. A., and SagiEisenberg, R. (2001). Synaptotagmin regulates mast cell functions. Immunol. Rev. 179, 25-34.

Baumgartner, R. A., Yamada, K., Deramo, V. A., and Beaven, M. A. (1994). Secretion of TNF from a rat mast cell line is a brefeldin A-sensitive and a calcium/protein kinase C-regulated process. J. Immunol. 153, 2609-2617.

Beghdadi, W., Madjène, L. C., Benhamou, M., Charles, N., Gautier, G., Launay, P., and Blank, U. (2011). Mast cells as cellular sensors in inflammation and immunity. Front. Immun. 2, 37. doi:10.3389/fimmu.2011.00037

Behrendorff, N., Dolai, S., Hong, W., Gaisano, H. Y., and Thorn, P. (2011).

the vesicular carriers involved in chemokine/cytokine secretion (Figure 3). Recent data suggest a highly complex profile of vesicular carriers and involved SNARE proteins that may not follow a standardized scheme. In addition to the core fusion proteins, mast cells also express a series of accessory molecules that regulate SNARE assembly. These may act as "gatekeepers" of the fusion reaction holding effectors in an inactive state or by coupling the fusion machinery to cell signaling in order to fine tune the transition to a fusion competent state. Given the potentially dangerous nature of an inappropriate activation of this machinery, the development of hierarchically organized regulatory levels is advantageous. Thus, besides effectors that directly trigger the fusion reaction, proteins involved in granule transport, granule docking and priming have co-evolved to provide multiple layers of regulation. Still, little is known, of how these proteins are related to early signaling events, although some basic connections, such as the phosphorylation of SNAP-23 by IKK and the responsiveness of certain processes to calcium signals have been described.

The understanding of the molecular machinery has important therapeutic potential. Indeed, it has become clear that during a generalized inflammatory reaction, multiple receptors and pathways are involved, many of these converge to trigger the secretion of inflammatory mediators. Thus, targeting the late fusion machinery clearly represents a strategy able to interfere with the activation of multiple receptors and limit their effect on mediator secretion.

\section{ACKNOWLEDGMENTS}

This work was supported by the COST Action BM1007 (Mast cells and basophils - targets for innovative therapies) of the European Community.

Vesicle-associated membrane protein 8 (VAMP8) is a SNARE (soluble N-ethylmaleimide-sensitive factor attachment protein receptor) selectively required for sequential granule-to-granule fusion. J. Biol. Chem. 286, 29627-29634.

Benhamou, M., and Blank, U. (2010). Stimulus-secretion coupling by high-affinity IgE receptor: new developments. FEBS Lett. 584, 4941-4948.

Bennett, M. K., and Scheller, R. H. (1993). The molecular machinery for secretion is conserved from yeast to neurons. Proc. Natl. Acad. Sci. U.S.A. 90, 2559-2563.

Bhaskar, K., Shareef, M. M., Sharma, V. M., Shetty, A. P., Ramamohan, Y., Pant, H. C., Raju, T. R., and Shetty, K. T. (2004). Co-purification and localization of Munc18-1 (p67) and Cdk5 with neuronal cytoskeletal proteins. Neurochem. Int. 44, 35-44.

Bischoff, S. C. (2007). Role of mast cells in allergic and non-allergic immune responses: comparison of human and murine data. Nat. Rev. Immunol. 7, 93-104.
Bjerke, T., Gaustadnes, M., Nielsen, S., Nielsen, L. P., Schiotz, P. O., Rudiger, N., Reimert, C. M., Dahl, R., Christensen, I., and Poulsen, L. K. (1996). Human blood eosinophils produce and secrete interleukin 4 . Respir. Med. 90, 271-277.

Blank, U. (2011). The mechanisms of exocytosis in mast cells. $A d v$. Exp. Med. Biol. 716, 107-122.

Blank, U., Cyprien, B., MartinVerdeaux, S., Paumet, F., Pombo, I., Rivera, J., Roa, M., and Varin-Blank, N. (2002). SNAREs and associated regulators in the control of exocytosis in the RBL-2H3 mast cell line. Mol. Immunol. 38, 1341-1345.

Blank, U., and Rivera, J. (2004). The ins and outs of IgE-dependent mastcell exocytosis. Trends Immunol. 25, 266-273.

Blott, E. J., and Griffiths, G. M. (2002). Secretory lysosomes. Nat. Rev. Mol. Cell Biol. 3, 122-131.

Bock, J. B., Matern, H. T., Peden, A. A., and Scheller, R. H. (2001). A genomic perspective on membrane compartment organization. Nature 409, 839-841. 
Burgoyne, R. D., Barclay, J. W., Ciufo, L. F., Graham, M. E., Handley, M. T., and Morgan, A. (2009). The functions of Munc18-1 in regulated exocytosis. Ann. N. Y. Acad. Sci. 1152, 76-86.

Calafat, J., Janssen, H., Stahle-Backdahl, M., Zuurbier, A. E., Knol, E. F., and Egesten, A. (1997). Human monocytes and neutrophils store transforming growth factor-alpha in a subpopulation of cytoplasmic granules. Blood 90, 1255-1266.

Carr, C. M., and Rizo, J. (2010). At the junction of SNARE and SM protein function. Curr. Opin. Cell Biol. 22, 488-495.

Castle, J. D., Guo, Z., and Liu, L. (2002). Function of the t-SNARE SNAP23 and secretory carrier membrane proteins (SCAMPs) in exocytosis in mast cells. Mol. Immunol. 38, 1337-1340.

Chapman, E. R. (2008). How does synaptotagmin trigger neurotransmitter release? Annu. Rev. Biochem. 77, 615-641.

Chua, J. J., Butkevich, E., Worseck, J. M., Kittelmann, M., Gronborg, M., Behrmann, E., Stelzl, U., Pavlos, N. J., Lalowski, M. M., Eimer, S., Wanker, E. E., Klopfenstein, D. R., and Jahn, R. (2012). Phosphorylationregulated axonal dependent transport of syntaxin 1 is mediated by a Kinesin-1 adapter. Proc. Natl. Acad. Sci. U.S.A. 109, 5862-5867.

Cohen, F. S., and Melikyan, G. B. (2004). The energetics of membrane fusion from binding, through hemifusion, pore formation, and pore enlargement. J. Membr. Biol. 199, 1-14.

Coppola, T., Perret-Menoud, V., Gattesco, S., Magnin, S., Pombo, I., Blank, U., and Regazzi, R. (2002). The death domain of Rab3 guanine nucleotide exchange protein in GDP/GTP exchange activity in living cells. Biochem. J. 362, 273-279.

Cote, M., Menager, M. M., Burgess, A., Mahlaoui, N., Picard, C., Schaffner, C., Al-Manjomi, F., Al-Harbi, M., Alangari, A., Le Deist, F., Gennery, A. R., Prince, N., Cariou, A., Nitschke, P., Blank, U., El-Ghazali, G., Menasche, G., Latour, S., Fischer, A., and De Saint Basile, G. (2009). Munc18-2 deficiency causes familial hemophagocytic lymphohistiocytosis type 5 and impairs cytotoxic granule exocytosis in patient NK cells. J. Clin. Invest. 119, 3765-3773.

Danglot, L., Zylbersztejn, K., Petkovic, M., Gauberti, M., Meziane, H., Combe, R., Champy, M. F., Birling, M. C., Pavlovic, G., Bizot, J. C., Trovero, F., Della Ragione, F., ProuxGillardeaux, V., Sorg, T., Vivien, D.,
D'esposito, M., and Galli, T. (2012). Absence of TI-VAMP/Vamp7 leads to increased anxiety in mice. J. Neurosci. 32, 1962-1968.

Dascher, C., Ossig, R., Gallwitz, D., and Schmitt, H. D. (1991). Identification and structure of four yeast genes (SLY) that are able to suppress the functional loss of YPT1, a member of the RAS superfamily. Mol. Cell. Biol. 11, 872-885.

Davletov, B., Connell, E., and Darios, F. (2007). Regulation of SNARE fusion machinery by fatty acids. Cell. Mol. Life Sci. 64, 1597-1608.

Dvorak, A. M. (2005). Piecemeal degranulation of basophils and mast cells is effected by vesicular transport of stored secretory granule contents. Chem. Immunol. Allergy 85, 135-184.

Elstak, E. D., Neeft, M., Nehme, N. T., Voortman, J., Cheung, M., Goodarzifard, M., Gerritsen, H. C., Van Bergen En Henegouwen, P. M., Callebaut, I., De Saint Basile, G., and Van Der Sluijs, P. (2011). The munc13-4-rab27 complex is specifically required for tethering secretory lysosomes at the plasma membrane. Blood 118, 1570-1578.

Feldmann, J., Callebaut, I., Raposo, G., Certain, S., Bacq, D., Dumont, C., Lambert, N., Ouachee-Chardin, M., Chedeville, G., Tamary, H., MinardColin, V., Vilmer, E., Blanche, S., Le Deist, F., Fischer, A., and De Saint Basile, G. (2003). Munc13-4 is essential for cytolytic granules fusion and is mutated in a form of familial hemophagocytic lymphohistiocytosis (FHL3). Cell 115, 461-473.

Feuser, K., Thon, K. P., Bischoff, S. C., and Lorentz, A. (2012). Human intestinal mast cells are a potent source of multiple chemokines. Cytokine 58, 178-185.

Fletcher, A. I., Shuang, R., Giovannucci, D. R., Zhang, L., Bittner, M. A., and Stuenkel, E. L. (1999). Regulation of exocytosis by cyclindependent kinase 5 via phosphorylation of Munc18. J. Biol. Chem. 274, 4027-4035.

Frank, S. P., Thon, K. P., Bischoff, S. C., and Lorentz, A. (2011). SNAP23 and syntaxin-3 are required for chemokine release by mature human mast cells. Mol. Immunol. 49, 353-358.

Fukuda, M., Imai, A., Nashida, T., and Shimomura, H. (2005). Slp4a/granuphilin-a interacts with syntaxin-2/3 in a Munc18-2dependent manner. J. Biol. Chem. 280, 39175-39184.

Galli, S., Dvorak, A., and Dvorak, H. (1984). Basophils and Mast
Cells: Morphologic Insights into their Biology, Secretory Patterns, and Function. Prog. Allergy 34, 1-141.

Gandhi, S. P., and Stevens, C. F. (2003). Three modes of synaptic vesicular recycling revealed by single-vesicle imaging. Nature 423, 607-613.

Glick, B. S., and Nakano, A. (2009) Membrane traffic within the Golgi apparatus. Annu. Rev. Cell Dev. Biol. 25, 113-132.

Goishi, K., Mizuno, K., Nakanishi, H., and Sasaki, T. (2004). Involvement of Rab27 in antigen-induced histamine release from rat basophilic leukemia 2H3 cells. Biochem. Biophys. Res. Commun. 324, 294-301.

Gordon, J. R., and Galli, S. J. (1990). Mast cells as a source of both preformed and immunologically inducible TNF-alpha/cachectin. Nature 346, 274-276.

Gordon, J. R., and Galli, S. J. (1991). Release of both preformed and newly synthesized tumor necrosis factor alpha (TNF-alpha)/cachectin by mouse mast cells stimulated via the Fc epsilon RI. A mechanism for the sustained action of mast cell-derived TNF-alpha during IgEdependent biological responses. J. Exp. Med. 174, 103-107.

Grimberg, E., Peng, Z., Hammel, I., and Sagi-Eisenberg, R. (2003). Synaptotagmin III is a critical factor for the formation of the perinuclear endocytic recycling compartment and determination of secretory granules size. J. Cell. Sci. 116, 145-154.

Guo, Z., Liu, L., Cafiso, D., and Castle, D. (2002). Perturbation of a very late step of regulated exocytosis by a secretory carrier membrane protein (SCAMP2)-derived peptide. J. Biol. Chem. 277, 35357-35363.

Guo, Z., Turner, C., and Castle, D. (1998). Relocation of the t-SNARE SNAP-23 from lamellipodia-like cell surface projections regulates compound exocytosis in mast cells. Cell 94, 537-548.

Haberman, Y., Grimberg, E., Fukuda, M., and Sagi-Eisenberg, R. (2003). Synaptotagmin IX, a possible linker between the perinuclear endocytic recycling compartment and the microtubules. J. Cell. Sci. 116, 4307-4318.

Haberman, Y., Ziv, I., Gorzalczany, Y., Fukuda, M., and Sagi-Eisenberg, R. (2005). Classical protein kinase $\mathrm{C}(\mathrm{s})$ regulates targeting of synaptotagmin IX to the endocytic recycling compartment. J. Cell. Sci. 118, 1641-1649.

Haberman, Y., Ziv, I., Gorzalczany, Y., Hirschberg, K., Mittleman, L.,
Fukuda, M., and Sagi-Eisenberg, R. (2007). Synaptotagmin (Syt) IX is an essential determinant for protein sorting to secretory granules in mast cells. Blood 109, 3385-3392.

Hanson, P. I., Roth, R., Morisaki, H., Jahn, R., and Heuser, J. E. (1997). Structure and conformational changes in NSF and its membrane receptor complexes visualized by quick-freeze/deep-etch electron microscopy. Cell 90, 523-535.

Harrison, S. D., Broadie, K., Van De Goor, J., and Rubin, G. M. (1994). Mutations in the Drosophila Rop gene suggest a function in general secretion and synaptic transmission. Neuron 13, 555-566.

Hata, Y., and Südhof, T. (1995). A novel ubiquitous form of Munc-18 interacts with multiple syntaxins. J. Biol. Chem. 270, 13022-13028.

Hepp, R., Puri, N., Hohenstein, A. C., Crawford, G. L., Whiteheart, S. W., and Roche, P. A. (2005). Phosphorylation of SNAP-23 regulates exocytosis from mast cells. J. Biol. Chem. 280, 6610-6620.

Hibi, T., Hirashima, N., and Nakanishi, M. (2000). Rat basophilic leukemia cells express syntaxin-3 and VAMP7 in granule membranes. Biochem. Biophys. Res. Commun. 271, 36-41.

Higashio, H., Nishimura, N., Ishizaki, H., Miyoshi, J., Orita, S., Sakane, A., and Sasaki, T. (2008). Doc2 alpha and Munc13-4 regulate $\mathrm{Ca}(2$ () dependent secretory lysosome exocytosis in mast cells. J. Immunol. 180, 4774-4784.

Ho, A., Morishita, W., Atasoy, D., Liu, X., Tabuchi, K., Hammer, R. E., Malenka, R. C., and Sudhof, T. C. (2006). Genetic analysis of Mint/X11 proteins: essential presynaptic functions of a neuronal adaptor protein family. J. Neurosci. 26, 13089-13101.

Hodel, A. (1998). Snap-25. Int. J. Biochem. Cell Biol. 30, 1069-1073.

Hong, W. (2005). SNAREs and traffic. Biochim. Biophys. Acta 1744, 120-144

Hosono, R., Hekimi, S., Kamiya, Y., Sassa, T., Murakami, S., Nishiwaki, K., Miwa, J., Taketo, A., and Kodaira, K. (1992). The unc-18 gene encodes a novel protein affecting the kinetics of Acetylcholine metabolism in the nematode Caenorhabditis elegans. J. Neurochem. 58, 1517-1525.

Huse, M., Lillemeier, B. F., Kuhns, M. S., Chen, D. S., and Davis, M. M. (2006). $\mathrm{T}$ cells use two directionally distinct pathways for cytokine secretion. Nat. Immunol. 7, 247-255.

Huse, M., Quann, E. J., and Davis, M. M. (2008). Shouts, whispers and 
the kiss of death: directional secretion in T cells. Nat. Immunol. 9, 1105-1111.

Hutagalung, A. H., and Novick, P. J. (2011). Role of Rab GTPases in membrane traffic and cell physiology. Physiol. Rev. 91, 119-149.

Huynh, H., Bottini, N., Williams, S., Cherepanov, V., Musumeci, L., Saito, K., Bruckner, S., Vachon, E., Wang, X., Kruger, J., Chow, C. W., Pellecchia, M., Monosov, E., Greer, P. A., Trimble, W., Downey, G. P., and Mustelin, T. (2004). Control of vesicle fusion by a tyrosine phosphatase. Nat. Cell Biol. 6, 831-839.

Itakura, M., Misawa, H., Sekiguchi, M., Takahashi, S., and Takahashi, M. (1999). Transfection analysis of functional roles of complexin I and II in the exocytosis of two different types of secretory vesicles. Biochem. Biophys. Res. Commun. 265, 691-696.

Kalesnikoff, J., and Galli, S. J. (2008). New developments in mast cell biology. Nat. Immunol. 9, 1215-1223.

Kanda, H., Tamori, Y., Shinoda, H., Yoshikawa, M., Sakaue, M., Udagawa, J., Otani, H., Tashiro, F., Miyazaki, J., and Kasuga, M. (2005). Adipocytes from Munc18c-null mice show increased sensitivity to insulin-stimulated GLUT4 externalization. J. Clin. Invest. 115, 291-301.

Kandere-Grzybowska, K., Letourneau, R., Kempuraj, D., Donelan, J., Poplawski, S., Boucher, W., Athanassiou, A., and Theoharides, T. C. (2003). IL-1 induces vesicular secretion of IL-6 without degranulation from human mast cells. J. Immunol. 171, 4830-4836.

Kapp-Barnea, Y., Melnikov, S., Shefler, I., Jeromin, A., and Sagi-Eisenberg, R. (2003). Neuronal calcium sensor1 and phosphatidylinositol 4-kinase beta regulate $\mathrm{IgE}$ receptor-triggered exocytosis in cultured mast cells. $J$. Immunol. 171, 5320-5327.

Kapp-Barnea, Y., Ninio-Many, L., Hirschberg, K., Fukuda, M., Jeromin, A., and Sagi-Eisenberg, R. (2006). Neuronal calcium sensor-1 and phosphatidylinositol 4-kinase beta stimulate extracellular signalregulated kinase $1 / 2$ signaling by accelerating recycling through the endocytic recycling compartment. Mol. Biol. Cell 17, 4130-4141.

Kimura, N., Shiraishi, S., Mizunashi, K., Ohtsu, H., and Kimura, I. (2001). Synaptotagmin I expression in mast cells of normal human tissues, systemic mast cell disease, and a human mast cell leukemia cell line. J. Histochem. Cytochem. 49, 341-346.
Koch, H., Hofmann, K., and Brose, N. (2000). Definition of Munc13-homology-domains and characterization of a novel ubiquitously expressed Munc13 isoform. Biochem. J. 349, 247-253.

Lacy, P., and Stow, J. L. (2011). Cytokine release from innate immune cells: association with diverse membrane trafficking pathways. Blood 118, 9-18.

Lam, P. P., Hyvarinen, K., Kauppi, M., Cosen-Binker, L., Laitinen, S., Keranen, S., Gaisano, H. Y., and Olkkonen, V. M. (2007). A cytosolic splice variant of Cab45 interacts with Munc18b and impacts on amylase secretion by pancreatic acini. Mol. Biol. Cell 18, 2473-2480.

Li, W., Ma, C., Guan, R., Xu, Y., Tomchick, D. R., and Rizo, J. (2011). The crystal structure of a Munc13 Cterminal module exhibits a remarkable similarity to vesicle tethering factors. Structure 19, 1443-1455.

Lippert, U., Ferrari, D. M., and Jahn, R. (2007). Endobrevin/VAMP8 mediates exocytotic release of hexosaminidase from rat basophilic leukaemia cells. FEBS Lett. 581, 3479-3484.

Liu, L., Guo, Z., Tieu, Q., Castle, A., and Castle, D. (2002). Role of secretory carrier membrane protein SCAMP2 in granule exocytosis. Mol. Biol. Cell 13, 4266-4278.

Ma, C., Li, W., Xu, Y., and Rizo, J. (2011). Munc13 mediates the transition(from )the closed syntaxinMunc18 complex to the SNARE complex. Nat. Struct. Mol. Biol. 18, 542-549.

Mahmudi-Azer, S., Velazquez, J. R., Lacy, P., Denburg, J. A., and Moqbel, R. (2000). Immunofluorescence analysis of cytokine and granule protein expression during eosinophil maturation from cord blood-derived CD34 progenitors. J. Allergy Clin. Immunol. 105, 1178-1184.

Martin-Verdeaux, S., Pombo, I., Iannascoli, B., Roa, M., Varin-Blank, N., Rivera, J., and Blank, U. (2003). Analysis of Munc18-2 compartmentation in mast cells reveals a role for microtubules in granule exocytosis. J. Cell Sci. 116, 325-334.

Matsushita, K., Morrell, C. N., Cambien, B., Yang, S. X., Yamakuchi, M., Bao, C., Hara, M. R., Quick, R. A., Cao, W., O’rourke, B., Lowenstein, J. M., Pevsner, J., Wagner, D. D., and Lowenstein, C. J. (2003). Nitric oxide regulates exocytosis by S-nitrosylation of N-ethylmaleimide-sensitive factor. Cell 115, 139-150.

Maximov, A., Tang, J., Yang, X., Pang, Z. P., and Sudhof, T. C. (2009).
Complexin controls the force transfer from SNARE complexes to membranes in fusion. Science 323 , 516-521.

Melicoff, E., Sansores-Garcia, L., Gomez, A., Moreira, D. C., Datta, P., Thakur, P., Petrova, Y., Siddiqi, T., Murthy, J. N., Dickey, B. F., Heidelberger, R., and Adachi, R. (2009). Synaptotagmin-2 controls regulated exocytosis but not other secretory responses of mast cells. $J$. Biol. Chem. 284, 19445-19451.

Menager, M. M., Menasche, G., Romao, M., Knapnougel, P., Ho, C. H., Garfa, M., Raposo, G., Feldmann, J., Fischer, A., and De Saint Basile, G. (2007). Secretory cytotoxic granule maturation and exocytosis require the effector protein hMunc13-4. Nat. Immunol. 8, 257-267.

Misura, K. M. S., Scheller, R. H., and Weis, W. I. (2000). Threedimensional structure of the neuronal-Sec1-syntaxin la complex. Nature 404, 355-362.

Mizuno, K., Tolmachova, T., Ushakov, D. S., Romao, M., Abrink, M., Ferenczi, M. A., Raposo, G., and Seabra, M. C. (2007). Rab27b regulates mast cell granule dynamics and secretion. Traffic 8, 883-892.

Murray, R. Z., Kay, J. G., Sangermani, D. G., and Stow, J. L. (2005a). A role for the phagosome in cytokine secretion. Science 310, 1492-1495.

Murray, R. Z., Wylie, F. G., Khromykh, T., Hume, D. A., and Stow, J. L. (2005b). Syntaxin 6 and Vtilb form a novel SNARE complex, which is upregulated in activated macrophages to facilitate exocytosis of tumor necrosis Factor-alpha. J. Biol. Chem. 280, 10478-10483.

Nagai, Y., Tadokoro, S., Sakiyama, H., and Hirashima, N. (2011). Effects of synaptotagmin 2 on membrane fusion between liposomes that contain SNAREs involved in exocytosis in mast cells. Biochim. Biophys. Acta 1808, 2435-2439.

Nechushtan, H., Leitges, M., Cohen, C., Kay, G., and Razin, E. (2000). Inhibition of degranulation and interleukin-6 production in mast cells derived from mice deficient in protein kinase Cbeta. Blood 95, 1752-1757.

Neeft, M., Wieffer, M., De Jong, A. S., Negroiu, G., Metz, C. H., Van Loon, A., Griffith, J., Kriigsveld, J., Wulffraat, N., Koch, H., Heck, A. J., Brose, N., Kleijmeer, M., and Van Der Sluijs, P. (2005). Munc13-4 is an effector of rab27a and controls secretion of lysosomes in hematopoietic cells. Mol. Biol. Cell 16, 731-741.
Nigam, R., Sepulveda, J., Tuvim, M., Petrova, Y., Adachi, R., Dickey, B. F., and Agrawal, A. (2005). Expression and transcriptional regulation of Munc18 isoforms in mast cells. Biochim. Biophys. Acta 1728, 77-83.

Novick, P., Field, C., and Schekman, R. (1980). Identification of 23 complementation groups required for post-translational events in the yeast secretory pathway. Cell 21, 205-215.

Oberhauser, A. F., Monck, J. R., Balch, W. E., and Fernandez, J. M. (1992). Exocytotic fusion is activated by Rab3a peptides. Nature 360, 270-273.

Oh, E., Spurlin, B. A., Pessin, J. E., and Thurmond, D. C. (2005). Munc18c heterozygous knockout mice display increased susceptibility for severe glucose intolerance. Diabetes 54, 638-647.

Olszewski, M. B., Groot, A. J., Dastych, J., and Knol, E. F. (2007). TNF trafficking to human mast cell granules: mature chain-dependent endocytosis. J. Immunol. 178, 5701-5709.

Olszewski, M. B., Trzaska, D., Knol, E. F., Adamczewska, V., and Dastych, J. (2006). Efficient sorting of TNFalpha to rodent mast cell granules is dependent on $\mathrm{N}$-linked glycosylation. Eur. J. Immunol. 36, 997-1008.

Ono, S., Baux, G., Sekiguchi, M., Fossier, P., Morel, N. F., Nihonmatsu, I., Hirata, K., Awaji, T., Takahashi, S., and Takahashi, M. (1998). Regulatory roles of complexins in neurotransmitter release from mature presynaptic nerve terminals. Eur. J. Neurosci. 10, 2143-2152.

Pagan, J. K., Wylie, F. G., Joseph, S., Widberg, C., Bryant, N. J., James, D. E., and Stow, J. L. (2003). The t-SNARE syntaxin 4 is regulated during macrophage activation to function in membrane traffic and cytokine secretion. Curr. Biol. 13, 156-160.

Paumet, F., Le Mao, J., Martin, S., Galli, T., David, B., Blank, U., and Roa, M. (2000). Soluble NSF attachment protein receptors (SNAREs) in RBL$2 \mathrm{H} 3$ mast cells: functional role of syntaxin 4 in exocytosis and identification of a vesicle-associated membrane protein 8-containing secretory compartment. J. Immunol. 164, 5850-5857.

Pelletier, C., Guerin-Marchand, C., Iannascoli, B., Marchand, F., David, B., Weyer, A., and Blank, U. (1998). Specific signaling pathways in the regulation of TNF-alpha mRNA synthesis and TNF-alpha secretion in RBL-2H3 mast cells stimulated through the high affinity IgE receptor. Inflamm. Res. 47, 493-500. 
Peng, Z., Grimberg, E., and SagiEisenberg, R. (2002). Suppression of Synaptotagmin II restrains phorbolester-induced downregulation of protein kinase Calpha by diverting the kinase from a degradative pathway to the recycling endocytic compartment. J. Cell. Sci. 115, 3083-3092.

Pickett, J. A., and Edwardson, J. M. (2006). Compound exocytosis: mechanisms and functional significance. Traffic 7, 109-116.

Pombo, I., Martin-Verdeaux, S., Iannascoli, B., Le Mao, J., Deriano, L., Rivera, J., and Blank, U. (2001). IgE receptor type Idependent regulation of a Rab3Dassociated kinase: a possible link in the calcium-dependent assembly of SNARE complexes. J. Biol. Chem. 276, 42893-42900.

Pombo, I., Rivera, J., and Blank, U. (2003). Munc18-2/syntaxin3 complexes are spatially separated from syntaxin3-containing SNARE complexes. FEBS Lett. 550, 144-148.

Puri, N., and Roche, P. A. (2006). Ternary SNARE complexes are enriched in lipid rafts during mast cell exocytosis. Traffic 7, 1482-1494.

Puri, N., and Roche, P. A. (2008). Mast cells possess distinct secretory granule subsets whose exocytosis is regulated by different SNARE isoforms. Proc. Natl. Acad. Sci. U.S.A. 105, 2580-2585.

Pushparaj, P. N., Tay, H. K., Wang, C. C., Hong, W., and Melendez, A. J. (2009). VAMP8 is essential in anaphylatoxin-induced degranulation, TNF-alpha secretion, peritonitis, and systemic inflammation. J. Immunol. 183, 1413-1418.

Qiao, H., Andrade, M. V., Lisboa, F. A., Morgan, K., and Beaven, M. A. (2006). FcepsilonR1 and toll-like receptors mediate synergistic signals to markedly augment production of inflammatory cytokines in murine mast cells. Blood 107, 610-618.

Reim, K., Mansour, M., Varoqueaux, F., Mcmahon, H. T., Sudhof, T. C., Brose, N., and Rosenmund, C. (2001). Complexins regulate a late step in Ca2+-dependent neurotransmitter release. Cell 104, 71-81.

Richmond, J. E., Weimer, R. M., and Jorgensen, E. M. (2001). An open form of syntaxin bypasses the requirement for UNC-13 in vesicle priming. Nature 412, 338-341.

Riedel, D., Antonin, W., FernandezChacon, R., Alvarez De Toledo, G., Jo, T., Geppert, M., Valentijn, J. A., Valentijn, K., Jamieson, J. D., Sudhof, T. C., and Jahn, R. (2002). Rab3D is not required for exocrine exocyto- sis but for maintenance of normally sized secretory granules. Mol. Cell. Biol. 22, 6487-6497.

Rivera, J., and Gilfillan, A. M. (2006). Molecular regulation of mast cell activation. J. Allergy Clin. Immunol. 117, 1214-1225; quiz 1226.

Roa, M., Paumet, F., Lemao, J., David, B., and Blank, U. (1997). Involvement of the ras-like GTPase rab3d in RBL-2H3 mast cell exocytosis following stimulation via high affinity IgE receptors (Fc epsilon RI). $J$. Immunol. 159, 2815-2823.

Rosenmund, C., Sigler, A., Augustin, I., Reim, K., Brose, N., and Rhee, J. S. (2002). Differential control of vesicle priming and short-term plasticity by Munc13 isoforms. Neuron 33, 411-424.

Sagi-Eisenberg, R. (2007). The mast cell: where endocytosis and regulated exocytosis meet. Immunol. Rev. 217, 292-303.

Salinas, E., Ventura, J., Cordova, L. E., and Luis Quintanar, J. (2004). Presence of SNAP-25 in rat mast cells. Immunol. Lett. 95, 105-108.

Sander, L. E., Frank, S. P., Bolat, S., Blank, U., Galli, T., Bigalke, H., Bischoff, S. C., and Lorentz, A. (2008). Vesicle associated membrane protein (VAMP)-7 and VAMP-8, but not VAMP-2 or VAMP-3, are required for activation-induced degranulation of mature human mast cells. Eur. J. Immunol. 38, 855-863.

Shen, J., Tareste, D. C., Paumet, F., Rothman, J. E., and Melia, T. J. (2007). Selective activation of cognate SNAREpins by Sec1/Munc18 proteins. Cell 128, 183-195.

Smith, J., Thompson, N., Armstrong, J., Hayes, B., Crofts, A., Squire, J., Teahan, C., Upton, L., and Solari, R. (1997). Rat basophilic leukaemia (RBL) cells overexpressing rab3a have a reversible block in antigenstimulated exocytosis. Biochem. J. 323, 321-328.

Snyder, D. A., Kelly, M. L., and Woodbury, D. J. (2006). SNARE complex regulation by phosphorylation. Cell Biochem. Biophys. 45, 111-123.

Sollner, T., Bennett, M. K., Whiteheart, S. W., Scheller, R. H., and Rothman, J. E. (1993). A protein assemblydisassembly pathway in vitro that may correspond to sequential steps of synaptic vesicle docking, activation, and fusion. Cell 75, 409-418.

Stenmark, H. (2009). Rab GTPases as coordinators of vesicle traffic. Nat. Rev. Mol. Cell Biol. 10, 513-525.

Stinchcombe, J. C., and Griffiths, G. M. (2007). Secretory mechanisms in cell-mediated cytotoxicity. Annu. Rev. Cell Dev. Biol. 23, 495-517.
Stow, J. L., Low, P. C., Offenhauser, C., and Sangermani, D. (2009). Cytokine secretion in macrophages and other cells: pathways and mediators. Immunobiology 214, 601-612.

Stow, J. L., Manderson, A. P., and Murray, R. Z. (2006). SNAREing immunity: the role of SNAREs in the immune system. Nat. Rev. Immunol. 6, 919-929.

Sudhof, T. C. (2004). The synaptic vesicle cycle. Annu. Rev. Neurosci. 27, 509-547.

Sudhof, T. C., and Rizo, J. (2011). Synaptic vesicle exocytosis. Cold Spring Harb. Perspect. Biol. 3, a005637.

Sudhof, T. C., and Rothman, J. E. (2009). Membrane fusion: grappling with SNARE and SM proteins. Science 323, 474-477.

Sutton, R. B., Fasshauer, D., Jahn, R., and Brunger, A. T. (1998). Crystal structure of a SNARE complex involved in synaptic exocytosis at 2.4 a resolution. Nature 395, 347-353.

Suzuki, K., and Verma, I. M. (2008). Phosphorylation of SNAP-23 by IkappaB kinase 2 regulates mast cell degranulation. Cell 134, 485-495.

Tadokoro, S., Kurimoto, T., Nakanishi, M., and Hirashima, N. (2007). Munc18-2 regulates exocytotic membrane fusion positively interacting with syntaxin-3 in RBL-2H3 cells. Mol. Immunol. 44, 3427-3433.

Tadokoro, S., Nakanishi, M., and Hirashima, N. (2005). Complexin II facilitates exocytotic release in mast cells by enhancing $\mathrm{Ca} 2+$ sensitivity of the fusion process. J. Cell. Sci. 118 2239-2246.

Tadokoro, S., Nakanishi, M., and Hirashima, N. (2010). Complexin II regulates degranulation in RBL$2 \mathrm{H} 3$ cells by interacting with SNARE complex containing syntaxin-3. Cell. Immunol. 261, 51-56.

Takahashi, S., Ujihara, H., Huang, G. Z. Yagyu, K. I., Sanbo, M., Kaba, H., and Yagi, T. (1999). Reduced hippocampal LTP in mice lacking a presynaptic protein: complexin II. Eur. J. Neurosci. 11, 2359-2366.

Tellam, J., Mcintosh, S., and James, D. (1995). Molecular identification of two novel munc-18 isoforms expressed in non-neuronal Tissues. J. Biol. Chem. 270, 5857-5863.

Tiwari, N., Wang, C. C., Brochetta, C., Ke, G., Vita, F., Qi, Z., Rivera, J., Soranzo, M. R., Zabucchi, G., Hong, W., and Blank, U. (2008). VAMP8 segregates mast cell-preformed mediator exocytosis from cytokine trafficking pathways. Blood 111, 3665-3674.

Tuvim, M. J., Adachi, R., Chocano, J. F., Moore, R. H., Lampert, R. M.,
Zera, E., Romero, E., Knoll, B. J., and Dickey, B. F. (1999). Rab3D, a small GTPase, is localized on mast cell secretory granules and translocates to the plasma membrane upon exocytosis. Am. J. Respir. Cell Mol. Biol. 20, 79-89.

Vaidyanathan, V. V., Puri, N., and Roche, P. A. (2001). The last exon of SNAP-23 regulates granule exocytosis from mast cells. J. Biol. Chem. 276, 25101-25106.

Verhage, M., Maia, A. S., Plomp, J. J., Brussaard, A. B., Heeroma, J. H., Vermeer, H., Toonen, R. F., Hammer, R. E., Van Den Berg, T. K., Missler, M., Geuze, H. J., and Sudhof, T. C. (2000). Synaptic assembly of the brain in the absence of neurotransmitter secretion. Science 287, 864-869.

Wang, X., Huynh, H., Gjorloff-Wingren, A., Monosov, E., Stridsberg, M., Fukuda, M., and Mustelin, T. (2002). Enlargement of secretory vesicles by protein tyrosine phosphatase PTP-MEG2 in rat basophilic leukemia mast cells and Jurkat $\mathrm{T}$ cells. J. Immunol. 168, 4612-4619.

Wierda, K. D., Toonen, R. F., De Wit, H., Brussaard, A. B., and Verhage, M. (2007). Interdependence of PKCdependent and PKC-independent pathways for presynaptic plasticity. Neuron 54, 275-290.

Wong, S. H., Zhang, T., Xu, Y., Subramaniam, V. N., Griffiths, G., and Hong, W. (1998). Endobrevin, a novel synaptobrevin/VAMP-like protein preferentially associated with the early endosome. Mol. Biol. Cell 9, 1549-1563.

Woska, J. R. Jr., and Gillespie, M. E. (2011). Small-interfering RNAmediated identification and regulation of the ternary SNARE complex mediating RBL-2H3 mast cell degranulation. Scand. J. Immunol. 73, 8-17.

Yao, J., Gaffaney, J. D., Kwon, S. E., and Chapman, E. R. (2011). Doc2 is a $\mathrm{Ca} 2+$ sensor required for asynchronous neurotransmitter release. Cell 147, 666-677.

Zur Stadt, U., Rohr, J., Seifert, W., Koch, F., Grieve, S., Pagel, J., Strauss, J., Kasper, B., Nurnberg, G., Becker, C., Maul-Pavicic, A., Beutel, K., Janka, G., Griffiths, G., Ehl, S., and Hennies, H. C. (2009). Familial hemophagocytic lymphohistiocytosis type 5 (FHL-5) is caused by mutations in Munc18-2 and impaired binding to syntaxin 11. Am. J. Hum. Genet. 85, 482-492.

Zur Stadt, U., Schmidt, S., Kasper, B., Beutel, K., Diler, A. S., Henter, 
J. I., Kabisch, H., Schneppenheim, R., Nurnberg, P., Janka, G., and Hennies, H. C. (2005). Linkage of familial hemophagocytic lymphohistiocytosis (FHL) type-4 to chromosome 6q24 and identification of mutations in syntaxin 11. Hum. Mol. Genet. 14, 827-834.
Conflict of Interest Statement: The authors declare that the research was conducted in the absence of any commercial or financial relationships that could be construed as a potential conflict of interest.

Received: 11 April 2012; paper pending published: 25 April 2012; accepted:
17 May 2012; published online: 05 June 2012.

Citation: Lorentz A, Baumann A, Vitte J and Blank U (2012) The SNARE machinery in mast cell secretion. Front. Immun. 3:143. doi: 10.3389/fimmu.2012.00143 This article was submitted to Frontiers in Molecular Innate Immunity, a specialty of Frontiers in Immunology.
Copyright () 2012 Lorentz, Baumann, Vitte and Blank. This is an openaccess article distributed under the terms of the Creative Commons Attribution Non Commercial License, which permits non-commercial use, distribution, and reproduction in other forums, provided the original authors and source are credited. 